\title{
DISTRIBUIC̣ÃO, ABUNDĀNCIA RELATIVA E MOVIMENTOS SAZONAIS DE BAGRES MARINHOS (SILURIFORMES, ARIIDAE) NO ESTUÁRIO DA LAGOA DOS PATOS (RS), BRASIL
}

\author{
Francisco Gerson Araújo ${ }^{1}$
}

\begin{abstract}
Three ariid fish, Netuma barba, Netuma planifrons and Genidens genidens, use the estuary of the Patos Lagoon (320S), Rio Grande do Sul, Brazil, as a nursery and feeding ground in various stages of their life history. A comparative study was made of the temporal and spatial distribution and relative abundance. Seasonal movements were interpreted on the basis of distribution and abundance of the young of these coexisting sea catfishe. Monthly otter trawl samples were made between November, 1979 and April, 1983. Temperature, salinities and dissolved oxygen contents were taken at each of the 674 sample stations. All three species were caught in ample temperature $(12,1$ to $26,30 \mathrm{C})$, salinity $(0,3$ to $35,5 \%$ ) and dissolved oxygen $(4,7$ to $11,5 \mathrm{mg} / \mathrm{l})$ ranges. However, they were more abundant in stations of low temperature and in salinity with highly dissolved oxygen content. $\mathbf{N}$. barba was the most abundant catfish caught in the estuary, it constituted $81,9 \%$ in number and $81,4 \%$ in weight of all ariid trawl catches during the study. N. barba occurred throughout the estuary, from the adjacent coastal region to the upper reaches of the Patos Lagoon estuary near the liminetic zone. $\mathbf{N}$. planifrons occurred from adjacent coastal regions to low saline parts of the Patos Lagoon estuary, whereas G. genidens were distributed mainly in low saline and freshwater parts of the lagoon. Young-of-the-year $\mathbf{N}$. barba aggregated near of the entrance of the lagoon in fall and winter, then moved up to intermediary parts of the estuary in spring, and they went to the upper part of the estuary in summer. Yearlings $\mathbf{N}$. barba moved into the estuary in common with young-of-the-year but did not reach the coastal adjacent area. Young-of-the-year and yearling $\mathbf{N}$. planifrons moved in to the estuary as the same pattern as $\mathbf{N}$. barba but they became scarce during the late summer and early fall. G. genidens were scarcely captured in the estuary throughout the year. The spatial and temporal segregations among Netuma and Genidens were evident. A hypothetical model for the life history of $\mathbf{N}$. barba is suggested.
\end{abstract}

\section{INTRODUÇÃO}

A familia Ariidae compreende bagres de regiões tropicais e temperadas

Posto de Aqüicultura - Universidade Federal Rural do Rio de Janeiro - Km 47 - Rodovia Rio-São Paulo - 23.460 - Seropédica - Itaguaí/RJ. 
Revta bras. Zool.

quentes, marinhos, estuarinos e algumas espécies com distribuição em água doce (Figueiredo e Menezes, 1978; Taylor e Menezes, 1978). No Atlântico, todos os bagres são Ariidae (Jones et alii, 1978; Berra, 1981).

No estuário da Lagoa dos Patos, esta família (Fig. 1) é representada por Netuma barba (Lacepede, 1803), Netuma planifrons (Higuchi, Reis e Araújo, 1982) e Genidens genidens (Valenciennes, 1833). N. barba (= Tachysurus barbus) e Genidens genidens foram registrados em vários estudos para a costa do Rio Grande do Sul (Ihering, 1855; Eigenmann e Eigenmann, 1890; Ribeiro, 1915; Tommasi, 1965; Poli, 1973; Castello et alii, 1976 a 1978).

N. planifrons foi descrito recentemente por Higuchi, Reis e Araújo (1982) para a Lagoa dos Patos e litoral do Rio Grande do Sul. G. genidens ocorre na costa leste da América do Sul, possivelmente das Guianas ao Rio da Prata, e $N$. barba, da costa leste do Brasil ao Rio da Prata (Figueiredo e Menezes, 1978). É possível ainda, estender-se os limites de distribuição de $N$. barba, ao Sul até San Blas (40032'S), na Argentina (López e Bellisio,1965). Recentemente foi feito um registro desta espécie, ainda mais ao Sul (Sielfeld, 1979), em águas chilenas da entrada oriental do Estreito de Magalhães (54000'S).

As três espécies constituiram, aproximadamente, $20 \%$ em número e peso da captura total dos arrastos de fundo experimentais no estuário da Lagoa dos Patos, no período de dezembro de 1978 a dezembro de 1979 (Chao et alii, 1982).

Na pesca artesanal do Rio Grande do Sul, efetuada na Lagoa dos Patos, para os anos de 1980, 1981 e 1982 estes bagres constituíram em média, aproximadamente, $12 \%$ do peso total da captura de peixes (Superintendência do Desenvolvimento da Pesca - SUDEPE - Rio Grande, RS). Já na pesca industrial, realizada na plataforma continental deste Estado, estes bagres constituíram menos de $1 \%$ do peso total de peixes, conforme esta mesma fonte.

$\mathrm{O}$ conhecimento do ciclo de vida destes bagres é escasso. Sua coexistência no estuário poderia ser devido a estratégias de separação espacial ou temporal. Informações preliminares sobre distribuição e abundância de espécies da família Ariidae na região Sudeste do Brasil foram feitas por Craig (1980) e Mishima e Tanji (1981, 1982 e 1983a e b). Ihering (1885) relatou que Tachysurus barbus entra na Lagoa dos Patos, em novembro, desovando na embocadura de rios e regressando ao mar, em fevereiro e março. Segundo Reis (1982), N. barba migra do mar para a Lagoa dos Patos, em agosto e setembro, reproduzindo-se em águas menos salinas do estuário, entre o fim da primavera e início do verão.

Neste trabalho, aborda-se o ciclo de vida dos jovens de $N$. barba, N. planifrons e $G$. genidens no estuário da Lagoa dos Patos (RS), com base na distribuição e abundância relativa, o que serviu para interpretação dos movimentos sazonais. Também os fatores hidrográficos (temperatura, salinidade e oxigênio dissolvido) da água de fundo foram relacionados à distribuição, à abundância e aos movimentos sazonais, visando determinar possíveis correlações.

\section{ÁREA DE ESTUdo}

A área estudada compreende o estuário da Lagoa dos Patos, desde a região 
Vol. 5(4), 1988
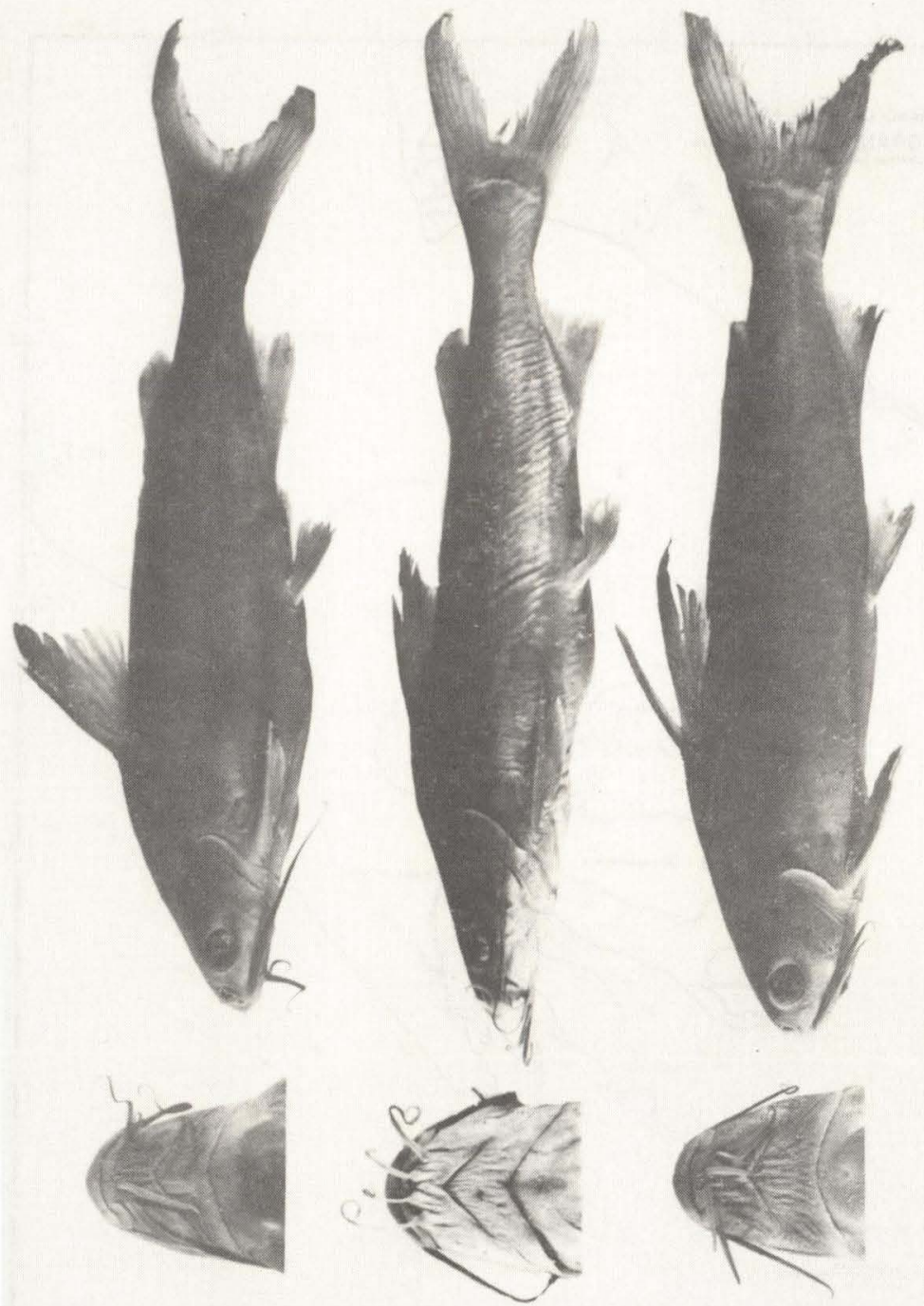

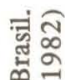

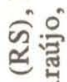

o 4

웡

‥

of ฯ

융 륭

สำ

ฮี

ชิ

을 $\leq \frac{1}{2}$

ठิ हี 声芯 굴 -

की

\% 항은 คी वี चี \& 可 ญ 웡 : य : 蛅各

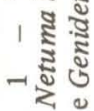

ن் 
Revta bras. Zool.

costeira adjacente à embocadura até, aproximadamente, $55 \mathrm{~km}$ lagoa a dentro, em direção norte (Fig. 2).

Todo o complexo fluvio-lagunar da Lagoa dos Patos tem área de 162.000 $\mathrm{km}^{2}$ (Herz, 1977), com uma única comunicação com o oceano, feita por um canal formado pelas molhes da barra do Rio Grande, com largura de 740 a $1.299 \mathrm{~m}$.

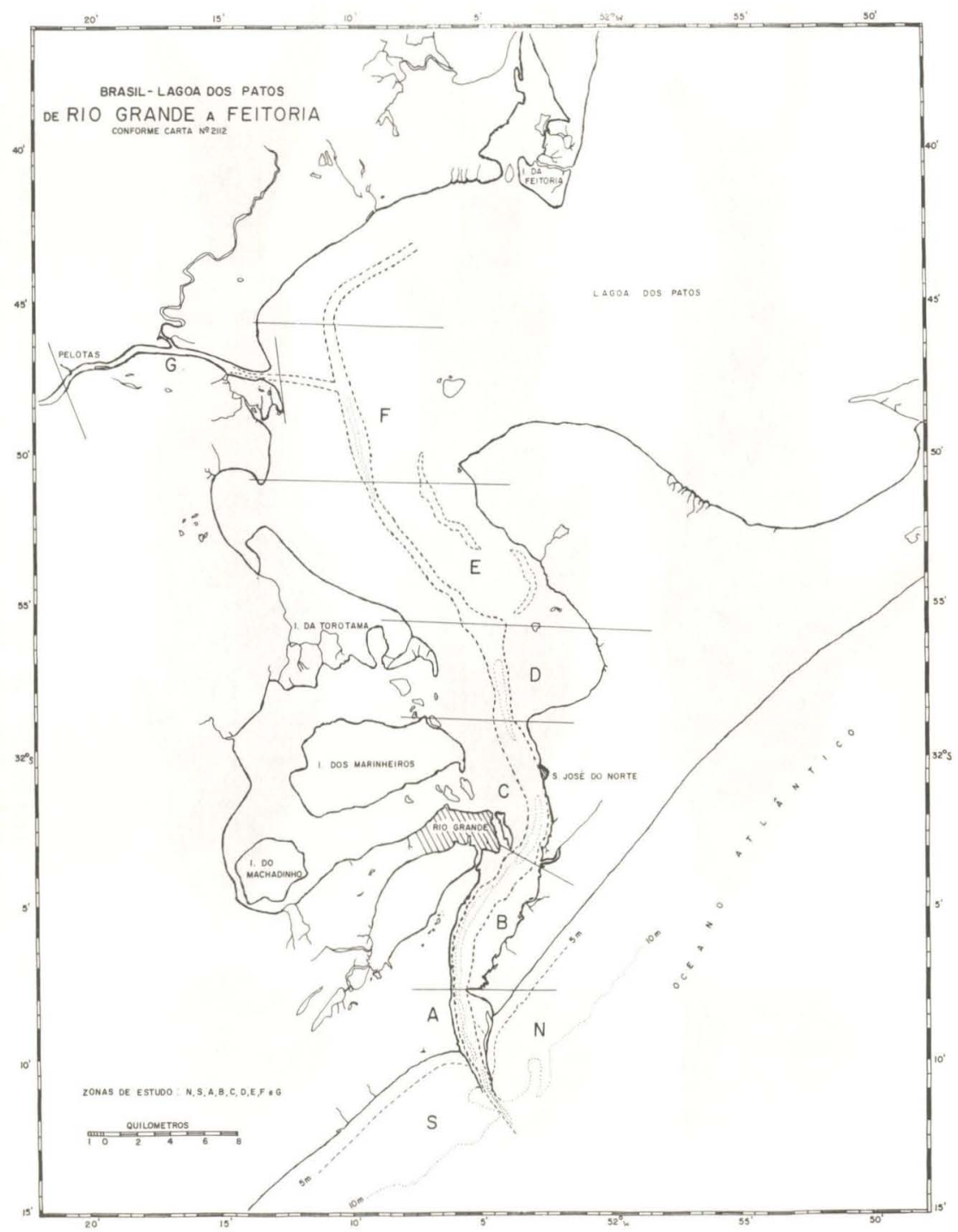

FIG. 2 - Estuário da Lagoa dos Patos, Área de Estudo. 
Vol. 5(4), 1988

A dinâmica das águas neste estuário é função, principalmente, da direção e intensidade dos ventos e da pluviosidade, sendo pequena a contribuição das marés, cuja amplitude média é de apenas 0,5 m (Mota, 1969).

Com relação à temperatura e à salinidade, o estuário é de homogêneo a mediamente estratificado, entretanto, podem ocorrer variações horárias na salinidade superiores a $10 \%$ devido às mudanças na intensidade e direção dos ventos (Kantin \& Baumgarten, 1982). A salinidade é influenciada pelas correntes, as quais dependem, principalmente, da direção e intensidade dos ventos, sendo muito variáveis na área, conforme se verificou durante as operações de campo. No inverno e fins do verão ocorrem as maiores precipitações pluviométricas, o que causa aumento das vazantes e diminuição de salinidade na região estuarial (Herz, 1977; Castello e Moller, 1978).

\section{MATERIAL E MÉTODOS}

\section{Programa de amostragem}

O material estudado foi proveniente de 674 amostragens regulares de arrasto de fundo, realizadas no período de novembro de 1979 a abril de 1983 (Tabela 1).

Nove zonas geográficas, designadas N, S, A, B, C, D, E, F e G foram consideradas na região estudada (Fig. 2). As zonas $\mathrm{N}$ e $\mathrm{S}$ correspondendo à área costeira adjacente à embocadura da lagoa, respectivamente, ao norte e sul da barra, com raio de cerca de $7 \mathrm{~km}$, centrado na entrada da barra; as zonas A e B correspondendo à embocadura da lagoa; as zonas C, D e E, correspondendo à área intermediária do estuário; e as zonas $\mathrm{F}$ e $\mathrm{G}$, correspondendo à área de menor salinidade do estuário (pré-límnica) ou cabeceira do estuário. A zona G correspondeu a aproximadamente $6 \mathrm{~km}$ de extensão do canal de.ligação da Lagoa dos Patos à Lagoa Mirim (Canal de São Gonçalo), em sua região adjacente à Lagos dos Patos.

Nas áreas do interior da lagoa, os arrastos foram realizados no canal de navegação ou em suas margens até uma profundidade de no mínimo $3 \mathrm{~m}$, devido à limitação pelo calado da lancha. A maior profundidade em toda área estudada foi de $24 \mathrm{~m}$, localizada na embocadura da lagoa.

O período, para amostrar toda área de estudo, foi de aproximadamente 4 dias, normalmente na última semana de cada mês. De novembro de 1979 a abril de 1981, as amostragens abrangeram basicamente, a região baixa do estuário (da área costeira à área intermediária); de abril de 1981 a abril de 1983, as amostragens compreenderam a região alta do estuário (da área da embocadura da lagoa à cabeceira ou área menos salina do estuário).

As amostragens foram realizadas em Lancha-Oceanográfica LARUS, de 15,3m de comprimento total, de propriedade da Fundação Universidade do Rio Grande. Utilizou-se rede de arrasto do fundo, com tralha superior possibilitando uma abertura máxima de entrada (boca) de $8 \mathrm{~m}$, malha de $12 \mathrm{~mm}$ de distância entre nós, e forro na região do saco com malha de $5 \mathrm{~mm}$.

Os arrastos foram realizados em sentido contrário ao da corrente, tiveram duração de 5 minutos no fundo e velocidade de 2,5 a 3 nós, cobrindo uma distância de $400( \pm 50) \mathrm{m}$, dependendo da velocidade da corrente. 
Revta bras. Zool.

Os fatores hidrográficos de temperatura, salinidade e oxigênio foram determinados na água de fundo, coletada com garrafa de Nansen. A temperatura $\left({ }^{\circ} \mathrm{C}\right)$ foi tomada com precisão de $0,1{ }^{\circ} \mathrm{C}$, com termômetro de mercúrio. A salinidade $(\% 0$ ) foi determinada com precisão de $0,1 \%$, pelo método de Knudsen; a a partir de outubro de 1981 optou-se pelo uso de salinômetro óptico. A concentração de oxigênio dissolvido $(\mathrm{mg} / \ell)$ foi medida com precisão de $0,1 \mathrm{mg} / \ell$, pelo

TAB. 1 - Número de arrastos de fundo (amostragens) por zonas, no estuário da Lagoa dos Patos (RS), no período de novembro de 1979 a abril de 1983 . Zonas: N, S, A, B, $\mathrm{C}, \mathrm{D}, \mathrm{E}, \mathrm{F}$ e $\mathrm{G}(\mathrm{N}$ e $\mathrm{S}=\operatorname{costa} ; \mathrm{A}, \mathrm{B} \ldots \mathrm{G}=\mathrm{da}$ embocadura para o interior da Lagos dos Patos).

\begin{tabular}{|c|c|c|c|c|c|c|c|c|c|c|}
\hline \multirow{2}{*}{ ANO/MES } & \multicolumn{9}{|c|}{ ZONAS } & \multirow{2}{*}{ TOT } \\
\hline & $\mathbf{N}$ & $\mathbf{S}$ & $\mathbf{A}$ & B & C & D & $\mathbf{E}$ & F & G & \\
\hline \multicolumn{11}{|l|}{1979} \\
\hline Nov. & 4 & 4 & 4 & 4 & 6 & 5 & 3 & - & - & 30 \\
\hline Dez. & 2 & 2 & 3 & 3 & 2 & 2 & - & - & - & 14 \\
\hline \multicolumn{11}{|l|}{1980} \\
\hline Abr. & 4 & 3 & 1 & - & - & - & - & - & - & 8 \\
\hline Mai. & - & - & 4 & 4 & 4 & 3 & 3 & - & - & 18 \\
\hline Jun. & 3 & 3 & 6 & 4 & 4 & 4 & 4 & - & - & 28 \\
\hline Jul. & 3 & 3 & 4 & 4 & 4 & 4 & 4 & - & - & 26 \\
\hline Ago. & 1 & - & 4 & 4 & 5 & 4 & 4 & - & - & 22 \\
\hline Set. & - & 3 & 4 & 4 & 4 & 4 & 5 & - & - & 24 \\
\hline Out. & 5 & 5 & 4 & 6 & 4 & 5 & 7 & - & - & 36 \\
\hline Nov. & 3 & 3 & 4 & 4 & 4 & 4 & 4 & - & - & 26 \\
\hline Dez. & 3 & 4 & 6 & 5 & 4 & 4 & 4 & - & - & 30 \\
\hline \multicolumn{11}{|l|}{1981} \\
\hline Jan. & 4 & 5 & 6 & 6 & 4 & 4 & 4 & - & - & 33 \\
\hline Fev. & - & - & 4 & 3 & 4 & 6 & 4 & - & - & 21 \\
\hline Mar. & 5 & 5 & 5 & 4 & 4 & 5 & 4 & - & - & 32 \\
\hline Abr. & - & - & 18 & 4 & 4 & 3 & 3 & - & - & 32 \\
\hline Jun. & - & - & 4 & - & - & - & - & - & - & 4 \\
\hline Ago. & - & - & 5 & 5 & 3 & 4 & 3 & 1 & 5 & 26 \\
\hline Dez. & - & - & 8 & 4 & 5 & 4 & 1 & - & - & 22 \\
\hline \multicolumn{11}{|l|}{1982} \\
\hline Jan. & 2 & 3 & 8 & 4 & 4 & 4 & 5 & 1 & 3 & 34 \\
\hline Fev. & - & 2 & 8 & 4 & 4 & 3 & 4 & 2 & 3 & 30 \\
\hline Abr. & - & - & 8 & 4 & - & - & - & - & - & 12 \\
\hline Mai. & - & 2 & 8 & 4 & 4 & 4 & 5 & 2 & 5 & 34 \\
\hline Jun. & - & - & 8 & - & - & - & - & - & - & 8 \\
\hline Jul. & - & - & 8 & 4 & 4 & 4 & - & - & - & 20 \\
\hline Ago. & - & - & 8 & 4 & 4 & 4 & 1 & 1 & 3 & 25 \\
\hline Set. & - & - & 8 & 3 & 4 & 5 & 3 & - & - & 23 \\
\hline Out. & - & - & 8 & 4 & 4 & 3 & 4 & 2 & 2 & 27 \\
\hline Dez. & - & - & 8 & - & - & - & - & - & - & 8 \\
\hline \multicolumn{11}{|l|}{1983} \\
\hline Abr. & - & - & 4 & 3 & 1 & 2 & 6 & 2 & 3 & 21 \\
\hline No Total de a & tra & & & & & & & & & 674 \\
\hline
\end{tabular}


Vol. 5(4), 1988

\begin{tabular}{cccccr} 
Zona & Outono & \multicolumn{2}{c}{ Estação do Ano } \\
Inverno & Primavera & Verão & Total \\
N & 157 & 159 & 166 & 192 & 39 \\
S & 9 & 7 & 12 & 11 & 47 \\
A & 10 & 6 & 15 & 16 & 178 \\
B & 48 & 47 & 32 & 51 & 192 \\
C & 23 & 25 & 25 & 29 & 94 \\
D & 17 & 24 & 26 & 27 & 94 \\
E & 17 & 24 & 26 & 27 & 85 \\
F & 21 & 16 & 26 & 22 & 11 \\
G & 14 & 2 & 2 & 3 & 24
\end{tabular}

método de Winkler (Strickland e Parsons, 1972). Para cada zona foram calculadas as médias mensais de temperatura, salinidade e oxigênio dissolvido.

Processamento das amostras

Todos os peixes foram identificados, contados, pesados e medidos, a bordo ou em laboratório. O comprimento total (CT), em milímetros, foi medido da ponta do focinho à parte mais posterior do lobo superior da nadadeira causal, e o peso, tomado em gramas. Nos arrastos com espécies com mais de 200 indivíduos, foram feitas sub-amostras para medições.

A abundância relativa dos três bagres foi calculada com base no somatório do número e/ou peso dos indivíduos capturados, dividido pelo total de arrastos. Foi calculada a abundância nas zonas por mês e por estação do ano.

Foram feitas distribuições de frequêencias de comprimento para cada espécie, por mês e por estação do ano, agrupando-se os indivíduos em classes de comprimento total de $5 \mathrm{~mm}$. Estas distribuições também foram utilizadas como índice de abundância dos peixes nas zonas, uma veż que sempre se considerou a totalidade dos indivíduos ou grandes amostras dos mesmos em cada arrasto.

Interpretaram se os movimentos sazonais das espécies, através das distribuições de frequêencias de comprimento, por mês e por estação do ano, em cada uma das nove zonas (N, S, A, B, C, D, E, F e G). No estudo das distribuições sazonais considerou-se as seguintes estações do ano: outono (março a maio), inverno (junho a agosto), primavera (setembro a novembro) e verão (dezembro a fevereiro). Nas distribuições mensais foram considerados dois ciclos anuais (abril de 1980 a abril de 1981 e dezembro de 1981 a dezembro de 1982), nos quais as amostragens foram mais regulares durante todo o período estudado.

\section{RESULTADOS E DISCUSSÃO}

\section{Fatores hidrográficos}

A temperatura da água de fundo apresentou variação cíclica anual regular (Fig. 3). As maiores médias mensais foram registradas em janeiro $\left(26,3{ }^{\circ} \mathrm{C}\right)$ e as menores, em julho $\left(12,1^{\circ} \mathrm{C}\right)$.

Não se observaram diferenças de temperatura entre as zonas estudadas em um mesmo mês de amostragem. Por outro lado, mudanças sazonais foram evi- 
Revta bras. Zool.

dentes, com elevações no período setembro/outubro/novembro e diminuições em abril/maio/junho (Fig. 3). Mudanças de temperaturas provavelmente estão relacionadas aos movimentos sazonais de peixes, especialmente, aqueles que fazem dos estuários locais de reprodução e criação durante suas fases da vida inicial (Markle, 1976).

Grandes oscilações nos valores médios da salinidade entre dois meses consecutivos foram observados. De maneira geral, a água do estuário foi mais salina no verão, e menos salina no inverno e início da primavera (Fig. 3), o que está relacionado às maiores alturas pluviométricas, comuns nestes períodos (Castello $\mathrm{e}$ Moller, 1978).

$\mathrm{Na}$ área costeira (zonas $\mathrm{N}$ e S), a salinidade esteve sempre acima de $20 \%$ durante todo o período observado. Os menores valores $(21 \%)$ foram registrados em julho de 1981 , e os maiores $(35,2 \%$ ), em maio de 1982 .

$\mathrm{Na}$ área estuarina do interior da lagoa, a salinidade variou de 0,3 a 35,5\% , sendo os menores valores registrados principalmente de junho a setembro, e os maiores, de dezembro a abril (Fig. 3); também muitas exceções neste padrão foram verificados devido, principalmente às mudanças na direção e intensidade dos ventos, conforme se observou durante as pescarias experimentais. $\mathrm{Na}$ zona $\mathrm{G}(\mathrm{Ca}-$ nal de São Gonçalo) a salinidade da água esteve sempre abaixo de 0,5\%, com exceção dos meses de fevereiro e abril de 1982 quando se registraram valores de 9,5 a $15 \%$, respectivamente. Tais registros foram considerados excessivamente elevados para a região.

A concentração de oxigênio dissolvido na água de fundo (Fig. 3) foi mais elevada nos meses frios (junho a novembro) e mais baixa nos meses quentes (dezembro a maio). A maior média foi $11,5 \mathrm{mg} / \ell$, (zona D), em junho de 1982 , e a menor, 4,7 mg/ / (zona C), em abril de 1982 (Fig. 3). Acreditamos que o oxigênio dissolvido não constitui um fator de limitação da distribuição e abundância das populações de peixes devido suas concentrações relativamente elevadas e pela grande influência de ventos na área estuarina.

\section{Distribuição espacial e temporal}

Os bagres marinhos são muito abundantes nos estuários onde permanecem durante parte de seu ciclo de vida, notadamente nos primeiros anos (Yañez Arancíbia et alii, 1976; Mishima e Tanji, 1982, 1983a).

No estuário da Lagoa dos Patos, as três espécies de bagres marinhos ocorreram durante todo o ano (Fig. 4). A abundância destes bagres, considerando todo o período e área estudados (Fig. 4), foi o seguinte (a percentagem do número de indivíduos em relação ao total de bagres marinhos segue entre parênteses): $N$. barba, 39,3 indivíduos por arrasto $(81,9 \%) ; N$. planifrons, 6,5 indivíduos por arrasto $(13,5 \%)$; e $G$.genidens, 2,2 indivíduos por arrasto $(4,6 \%)$. Com relação ao peso, foram os seguintes os valores encontrados: $N$. barba, 1.364 gramas por arrasto $(81,4 \%) ; N$. planifrons, 180 gramas por arrasto $(10,8 \%)$; e $G$. genidens, 132 gramas por arrasto $(7,8 \%)$.

As maiores abundâncias das espécies do gênero Netuma registraram-se no período de junho a dezembro (inverno e primavera), meses de temperaturas e salinidade mais baixas e elevados teores de oxigênio dissolvido (Fig. 4). Por outro lado, no mês de dezembro, quando os valores destes fatores ambientais são pra- 
Vol. 5(4), 1988

TEMPERATURA $\left({ }^{\circ} \mathrm{C}\right)$

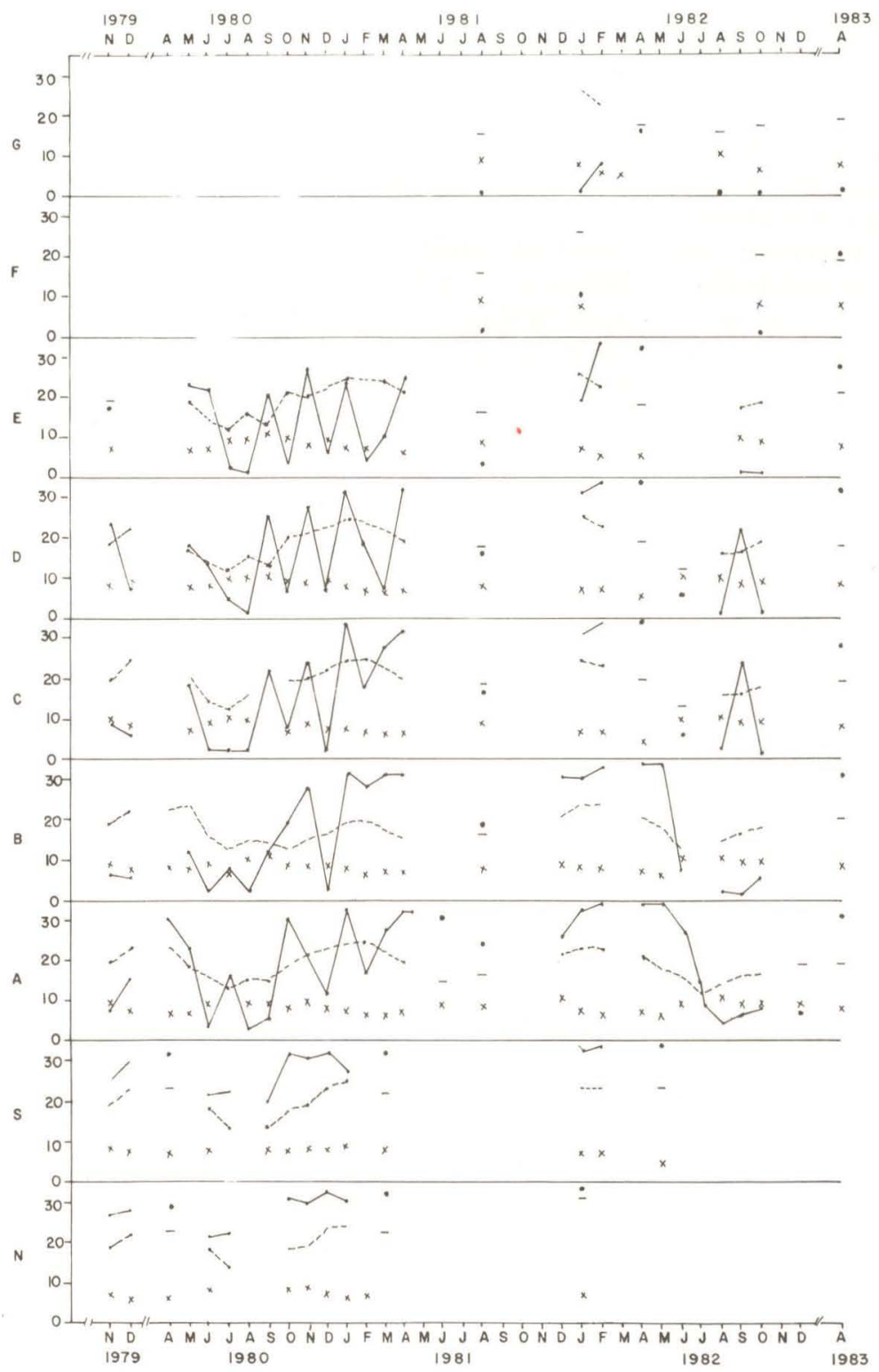

FIG. 3 - Médias mensais de temperatura, salinidade e oxigênio dissolvido em água do fundo do estuário da Lagoa dos Patos (RS), no período de novembro de 1979 a abril de 1983. 
Revta bras. Zool.

ticamente inversos, também foram registrados elevadas abundâncias de Netuma, o que torna pequena a correlação entre a abundância e estes fatores ambientais. G. genidens, o bagre marinho menos abundante no estuário da Lagoa dos Patos, não apresentou picos sazonais de abundância, porém em dezembro registraramse sempre suas maiores ocorrências.

Bleber e Blaber (1980) reportaram que a salinidade e a temperatura não influenciam na abundância de peixes jovens nos estuários, o que está de acordo com nossas observações. Já Villaseñor (1972), Lara-Dominguez et alii (1981) citam que, dos fatores ambientais, principalmente a salinidade influencia na abundância destas espécies.

Mishima e Tanji (1983a) estudando as influências da temperatura e salinidade na distribuição de Ariidae no complexo estuarino lagunar de Cananéia, encontraram não haver variação significativa na temperatura. Com respeito à salinidade, não encontraram relação de dependência para G. genidens; $N$. barba jovens foram indicados ter preferência por elevada salinidade $(8,1$ a $32 \%)$, o que é atribuído ao comportamento das formas adultas desta espécie de viverem no mar aberto.

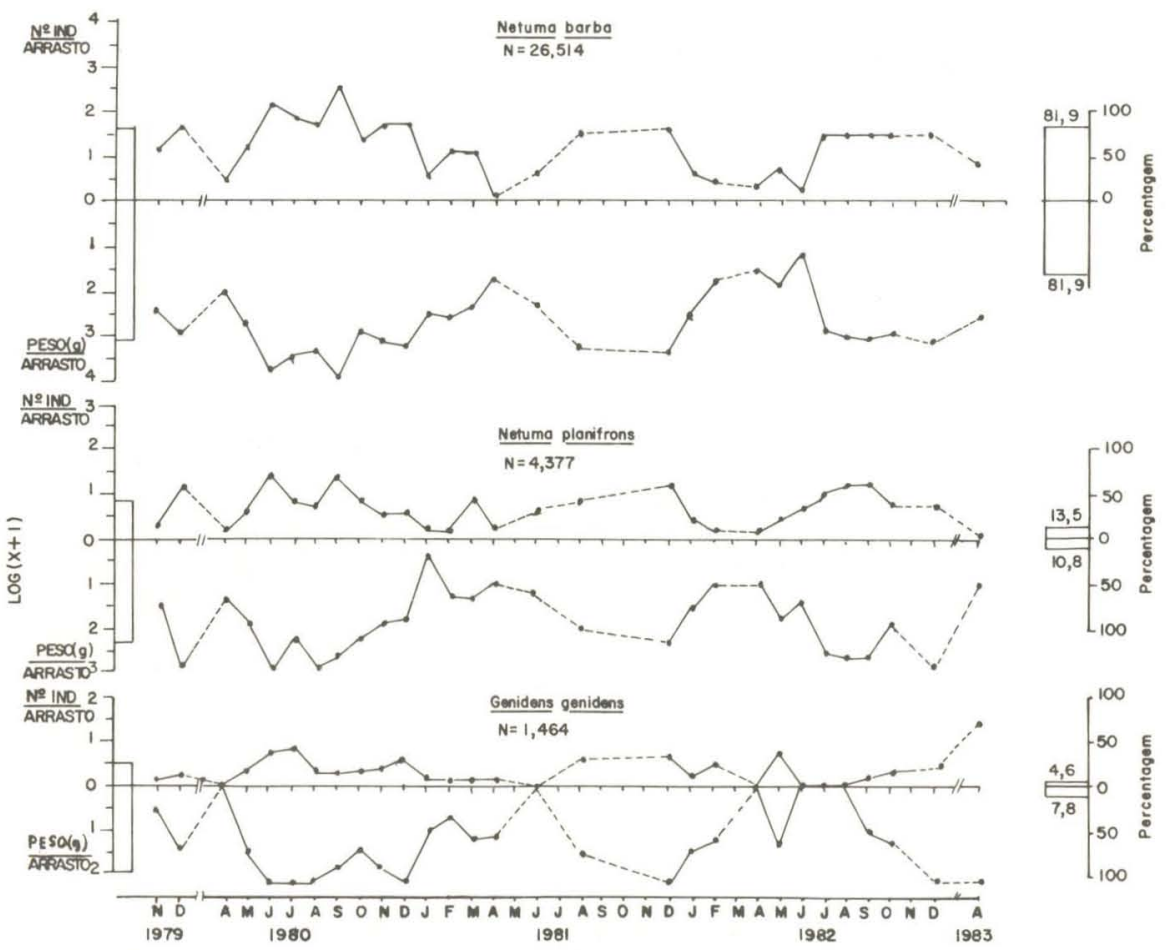

FIG. 4 - Abundância mensal de bagres marinhos (Ariidae) e percentagem de cada espécie, em número e peso de indivíduos por arrasto, no estuário da Lagoa dos Patos (RS), no período de novembro de 1979 a abril de 1983 . 
Vol. 5(4), 1988

Encontramos pequena correlação, embora significativa, entre a abundância dos três bagres marinhos e os fatores ambientais de temperatura, salinidade e oxigênio dissolvido (Tabela 2). A temperatura e a salinidade apresentaram-se inversamente proporcionais à abundância, e o oxigênio dissolvido apresentou-se diretamente proporcional. Os três bagres, basicamente, suportam uma grande variação destes três fatores ambientais.

TAB. 2 - Coeficiente de correlação de Pearson entre temperatura, salinidade e oxigênio dissolvido e abundância de bagres marinhos (Ariidae) no estuário da Lagoa dos Patos (RS), no período de abril de 1980 a abril de 1981.

\section{FATORES HIDROGRÁFICOS}

ABUNDĀNCIA

N. barba

N. planifrons

G. genidens
COEFICIENTE DE CORRELAÇÃO

TEMPERATURA SALINIDADE

$$
\begin{aligned}
& -0,33 \text { * } \\
& -0,24 \text { * } \\
& -0,18 \text { * }
\end{aligned}
$$

$$
\begin{aligned}
& -0,27 \star \\
& -0,20 \star \\
& -0,33 \star
\end{aligned}
$$

* Significantes ao nível de $95 \%$.

TAB. 3 - Número de indivíduos por arrasto de fundo de Netuma barba, por zonas e estações do ano, no estuário da Lagoa dos Patos (RS), no período de novembro de 1979 (primavera/1979) a abril de 1983 (outono/1983). Zonas: N, S, A, B, C, D, E, F e G $(\mathrm{N}$ e $\mathrm{S}=\operatorname{costa} ; \mathrm{A}, \mathrm{B}, \ldots \mathrm{G}=$ da embocadura para o interior da Lagoa dos Patos).

\section{ESTAÇÕES}

DO ANO

1979

Primavera

1980

Verão

Outono

Inverno

Primavera

1981

Verão

Outono

Inverno

Primavera

1982

Verão

Outono

Inverno

Primavera

1983

Verão

Outono
ZONAS

$\begin{array}{lllll}\text { C } & \text { D } & \text { E } & \text { F } & \text { G }\end{array}$

A B

85,8

12,2

18,4

4,3

11

4

3,6

4,8

5,1

8,1

3,4

1,8

1,8

15

\section{1,5}

2,0

0,4

4,7

0,45 *

0,28 *

0,29 *

\section{OXIGÊNIO \\ DISSOLVIDO}


Revta bras. Zool.

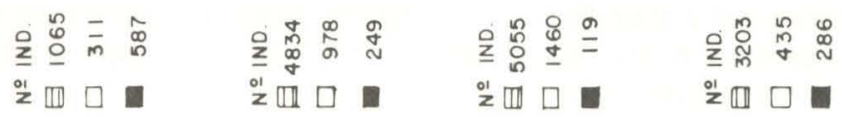

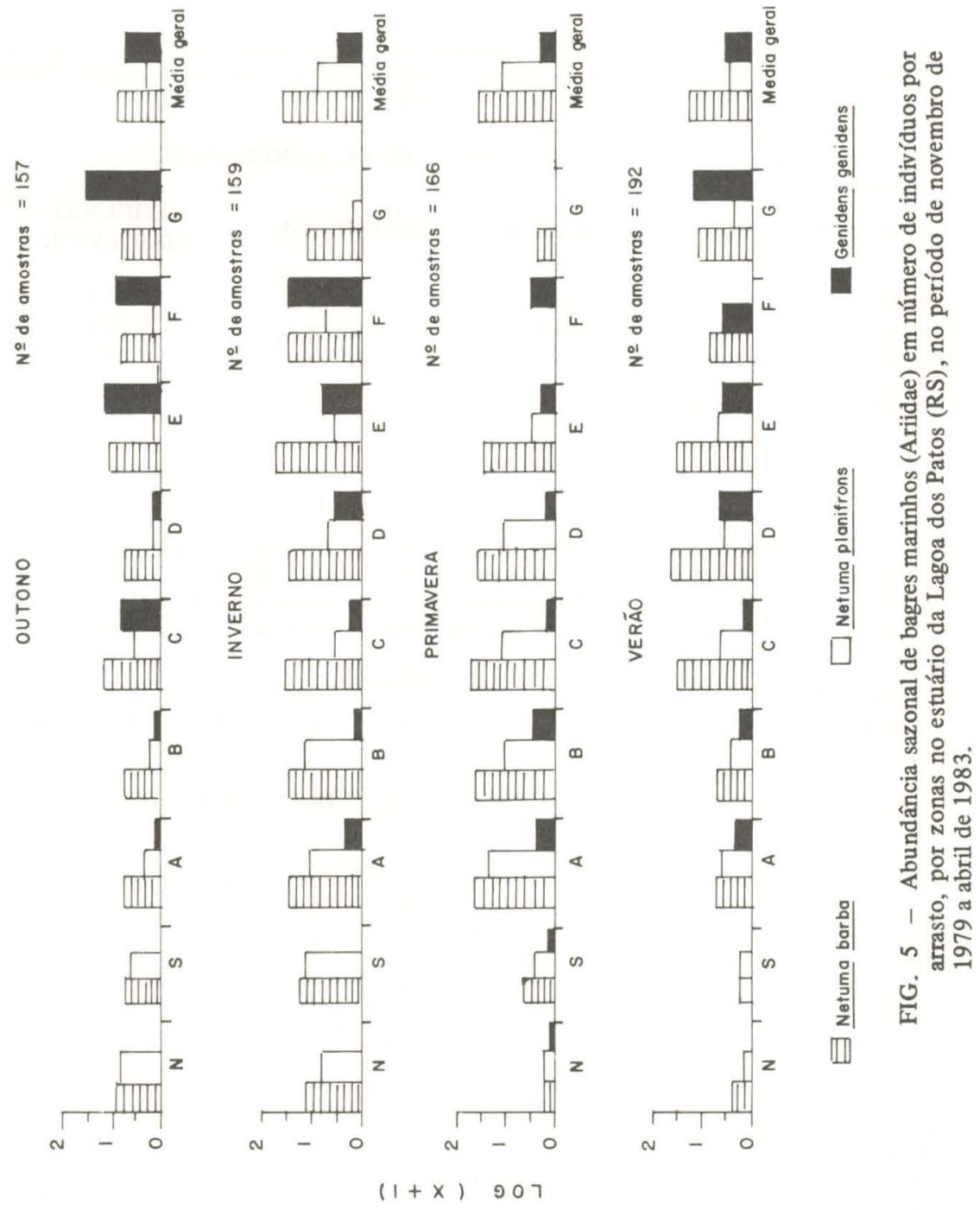


Vol. 5(4), 1988

TAB. 4 - Número de indivíduos por arrasto de fundo de Netuma planifrons, por zonas e estações do ano, no estuário da Lagoa dos Patos (RS), no período de novembro de 1979 (primavera/1979) a abril de 1983 (outono/1983). Zonas: N, S, A, B, C, D, E, F e $\mathrm{G}(\mathrm{N}$ e $\mathrm{S}=\operatorname{costa} ; \mathrm{A}, \mathrm{B} . . \mathrm{G}=$ da embocadura para o interior da Lagoa dos Patos).

\begin{tabular}{|c|c|c|c|c|c|c|c|c|c|}
\hline \multirow{2}{*}{$\begin{array}{c}\text { ESTAÇÕES } \\
\text { DO ANO }\end{array}$} & \multicolumn{9}{|c|}{ ZONAS } \\
\hline & $\mathbf{N}$ & S & A & B & C & D & E & $\mathbf{F}$ & G \\
\hline 1979 & & & & & & & & & \\
\hline $\begin{array}{l}\text { Primavera } \\
1980\end{array}$ & 1,8 & 1,0 & 71,5 & 85,8 & 12,2 & 18,4 & 4,3 & - & - \\
\hline Verão & 1 & 0 & 0 & 11 & 4 & 1,5 & - & - & - \\
\hline Outono & 0 & 0 & 3,6 & 4,8 & 1,8 & 2,0 & 1,0 & - & - \\
\hline Inverno & 5,6 & 13 & 9,8 & 5,1 & 1,8 & 0,4 & 0,7 & - & - \\
\hline $\begin{array}{l}\text { Primavera } \\
1981\end{array}$ & 0 & 1,7 & 8,1 & 3,4 & 15 & 4,7 & 1,9 & - & - \\
\hline Verão & 0 & 1,1 & 1,4 & 0,4 & 1,3 & 1,4 & 1,4 & - & - \\
\hline Outono & 12 & 8,8 & 3,5 & 1,5 & 0,5 & 0 & 0 & - & - \\
\hline Inverno & - & - & 1,8 & 3,5 & 2,0 & 14,5 & 10,3 & 7 & 0 \\
\hline $\begin{array}{l}\text { Primavera } \\
1982\end{array}$ & - & - & - & - & - & - & - & - & - \\
\hline Verão & 0 & 0 & 3,6 & 0,8 & 3,5 & 4,2 & 5,5 & 2,6 & 0,8 \\
\hline Outono & - & 0 & 0,3 & 1,1 & 9 & 3 & 0,2 & 0,5 & 0,4 \\
\hline Inverno & - & - & 13,4 & 38,3 & 2,9 & 0 & 0 & 0 & 0 \\
\hline $\begin{array}{l}\text { Primavera } \\
1983\end{array}$ & - & - & 48 & 1,6 & 1,3 & 10,6 & 0 & 0 & 0 \\
\hline Verão & - & - & 4,3 & - & - & - & - & - & - \\
\hline Outono & - & - & 0 & 0 & 1 & 0 & 0 & 0 & 0 \\
\hline
\end{tabular}

Foram comparadas as distribuições espaciais e temporais de jovens das três espécies (Fig. 5) visando determinar a repartição ecológica durante suas vidas no estuário da Lagoa dos Patos, tendo se observado que mudanças sazonais na abundância e distribuição das três espécies foram evidentes.

Jovens de $N$. barba e $N$. planifrons foram capturados em toda a região estuada (Fig. 5), enquanto G. genidens, somente nas áreas estuarinas do interior da lagoa, da embocadura à cabeceira do estuário (zonas A, B, C, D, E, F e G).

No outono, foram observadas pequenas abundâncias de bagres em toda área estudada (Fig. 5). $N$. barba e $N$. planifrons distribuíram-se em todo estuário e $G$. genidens só não foi registrado na área costeira (zonas N e S). N. barba foi mais abundante na área intermediária (zonas C, D e E), $N$. planifrons, na área costeira, e $G$. genidens, na cabeceira do estuário (zonas F e G). $N$. barba foi mais abundante na área intermediária do estuário no outono de 1980, 1982 e 1983 (Tabela 3). Excepcionalmente, no outono de 1981 foi mais abundante na área costeira. $N$. planifrons apresentou distribuição irregular nestes anos (Tabela 4); no outono de 1980 foi mais abundante na embocadura (zonas A e B), em 1981, na área costeira, e em 1982 e 1983, na área intermediária. Genidens genidens foi sempre mais abundante na cabeceira (Tabela 5). 
Revta bras. Zool.

TAB. 5 - Número de indivíduos por arrasto de fundo de Genidens genidens, por zonas e estações do ano, no estuário da Lagoa dos Patos (RS), no período de novembro de 1979 (primavera/1979) a abril de 1983 (outono/1983). Zonas: N, S, A, B, C, D, E, F e $\mathrm{G}(\mathrm{N}$ e $\mathrm{S}=\operatorname{costa} ; \mathrm{A}, \mathrm{B} . . \mathrm{G}=\mathrm{da}$ embocadura para o interior da Lagoa dos Patos).

\begin{tabular}{|c|c|c|c|c|c|c|c|c|c|}
\hline \multirow{2}{*}{$\begin{array}{c}\text { ESTAÇÕES } \\
\text { DO ANO }\end{array}$} & \multicolumn{9}{|c|}{ ZONAS } \\
\hline & $\mathbf{N}$ & $\mathbf{S}$ & $\mathbf{A}$ & B & C & D & $\mathbf{E}$ & $\mathbf{F}$ & G \\
\hline \multicolumn{10}{|l|}{1979} \\
\hline Primavera & 0 & 0,3 & 0,5 & 0,3 & 0 & 0 & 1,3 & - & - \\
\hline \multicolumn{10}{|l|}{1980} \\
\hline Verão & 0 & 0 & 0 & 0 & 0 & 0,2 & 0 & - & - \\
\hline Outono & - & - & 0,2 & 0,8 & 0 & 0 & 6,3 & - & - \\
\hline Inverno & - & - & 3 & 0,6 & 1,4 & 4,2 & 3,9 & - & - \\
\hline Primavera & 0,1 & 0 & 2,9 & 2,9 & 0,5 & 0,4 & 2,8 & - & - \\
\hline \multicolumn{10}{|l|}{1981} \\
\hline Verão & 0 & 0 & 1,7 & 1,1 & 0,4 & 1,3 & 2,7 & - & - \\
\hline Outono & 0 & 0 & 0,2 & 0 & 0,5 & 0,1 & 0,3 & - & - \\
\hline Inverno & - & - & 0 & 0 & 0 & 1,3 & 8 & 56 & 0,2 \\
\hline Primavera & - & - & - & - & - & - & - & - & - \\
\hline \multicolumn{10}{|l|}{1982} \\
\hline Verão & 0 & 0 & 0,1 & 0,1 & 0,5 & 6,5 & 2,0 & 0,3 & 12,3 \\
\hline Outono & - & 0 & 0 & 0 & 0 & 0 & 0 & 0 & 32 \\
\hline Inverno & - & - & 0 & 0 & 0 & 0 & 0 & 0 & 0 \\
\hline Primavera & - & - & 0 & 0 & 0,4 & 0,6 & 0,4 & 1,5 & 0 \\
\hline \multicolumn{10}{|l|}{1983} \\
\hline Verão & - & - & 1,5 & - & - & - & - & - & - \\
\hline Outono & - & - & 0 & 0 & 82 & 1 & 55,2 & 14 & 46,6 \\
\hline
\end{tabular}

No inverno, observou-se semelhante padrão de distribuição do outono para as três espécies, só que com abundâncias bem mais elevadas (Fig. 5). $N$. barba foi mais abundante na área intermediária, $N$. planifrons, na área costeira e embocadura, e G. genidens, na cabeceira e área intermediária. $N$. barba foi mais abundante nas áreas da embocadura e interme diária no inverno de 1980, 1981 e 1982 enquanto $N$. planifrons na embocadura em 1980 e 1982, e na área intermediária, em 1981 (Tabelas 3 e 4). G. genidens foi mais abundante na área intermediária no inverno de 1980 (neste período não foi amostrada a cabeceira do estuário), na cabeceira, em 1981, e esteve ausente do estuário, em 1982 (Tabela 5). Foi evidente, no outono e inverno, a separação espacial entre $N$. planifrons e $G$. genidens que apresentaram maiores abundâncias em áreas contíguas.

$\mathrm{Na}$ primavera, jovens dos três bagres marinhos concentraram-se na embocadura e área intermediária, e foram registrados neste período suas maiores abundâncias anuais (Fig. 5). N. barba foi mais abundante na embocadura, em 1979, e na área intermediária, em 1980 e 1982 (Tabela 3). Na primavera de 1981 não foram realizadas amostragens. $N$. planifrons foi mais abundante na embocadura, em 1979 e 1982; e na área intermediária, em 1980 (Tabela 4). G. genidens apresentou pequena abundância e distribuição uniforme em toda área estudada nesta estação do ano (Tabela 5). Houve uma evidente sobreposição espacial e 
Vol. 5(4), 1988

temporal dos três bagres marinhos nesta estação do ano, principalmente na área intermediária.

No verão, as ocorrências de bagres marinhos foram bem menores do que na estação anterior, denotando uma saída destes bagres da área de estudo (Fig. 5). As três espécies distribuiram-se em todo estuário, com exceção da área costeira onde suas ocorrências foram despreziveis. As maiores abundâncias foram registradas na área intermediária, constituída, principalmente de $N$. barba; na cabeceira, $G$. genidens foi a espécie mais abundante, declinando sua abundância das cabeceiras para a embocadura. $N$. barba (Tabela 3) foi mais abundante na área intermediária durante todo o período (1980 a 1982). $N$. planifrons apresentou pequena e uniforme abundância durante todo o período (Tabela 4). G. genidens, apesar de praticamente ausente nas amostragens em 1980 e pequena abundância em 1981, foi muito abundante nas cabeceiras do estuário em 1982 e 1983 (Tabela 5).

Em sumário, concluímos que $N$. barba é a espécie de distribuição mais ampla no estuário, predominando na área mais tipicamente mixohalina (embocadura e área intermediária). $N$. planifrons reparte a área costeira com $N$. barba e a embocadura e área intermediária com $N$. barba e G. genidens, sendo escasso na cabeceira, onde predomina $G$. genidens.

$N$. barba e $N$. planifrons são, provavelmente, espécies melhor adaptadas a estuários e, $G$. genidens, às zonas limítrofes entre cabeceira de estuário e água doce, embora todas estas espécies sejam, essencialmente, eurihalinas. Corroborando esta hipbtese verificamos que somente na cabeceira é onde se registrou abundância de $G$. genidens superior a $N$. barba e $N$. planifrons (Tabelas 3, 4 e 5).

Foram pouco relevantes as diferenças na distribuição por profundidade dos três bagres marinhos no estuário da Lagoa dos Patos, conforme observou Araújo (1983), comparando ocorrências destes peixes em profundidades superiores e inferiores a $10 \mathrm{~m}$.

\section{Tamanho e Movimentos Sazonais}

\section{Netuma barba}

Foram observados dois bem caracterizados grupos de tamanho (modas I e II) de $N$. barba, além de alguns indivíduos de maior tamanho que não chegaram a caracterizar moda (Figs. 6 e 7).

As modas I e II (Figs. 6 e 7) corresponderam às duas primeiras classes de idade, o que pode ser constatado através do acompanhamento, durante o ano, nos dois ciclos anuais, dessas classes modais. Os indivíduos da primeira classe modal (moda I), presentes nas capturas a partir de março, um ano depois (fevereiro/março) apresentam comprimento modal correspondendo à moda II. Esta última moda, também, pode ser acompanhada de março a dezenbro. Em janeiro e fevereiro, estes indivíduos foram escassos na área estudada. Também nestes dois meses não foi possível a visualização dos limites de tamanho modal devido à sobreposição das distribuições de freqüências de comprimento dos indivíduos da moda I e da moda II (Figs. 6 e 7).

Isto, mais o fato de $N$. barba desovar entre fins da primavera e início do ve- 
Revta bras. Zool.

rão (Thering, 1897; Reis, 1982) permite estabelecer que a moda I corresponde aos indivíduos no primeiro ano de vida, moda II representa os indivíduos no segundo ano de vida. Os indivíduos de comprimento total (CT) superior à moda II, são de idade acima de dois anos (Figs. 6 e 7).

$N$. barba apareceu nas amostragens em março (Figs. 6 e 7), apresentando $\mathrm{CT}=65 \mathrm{a} 90 \mathrm{~mm}(\overline{\mathrm{CT}}=75 \mathrm{~mm})$. Em dezembro, quando tinham aproximadamente 1 ano de idade, apresentavam $\mathrm{CT}=90$ a $135 \mathrm{~mm}(\overline{\mathrm{CT}}=100 \mathrm{~mm})$ enquanto os indivíduos de 2 anos de idade apresentavam $\mathrm{CT}=140$ a $200 \mathrm{~mm}(\overline{\mathrm{CT}}=150 \mathrm{~mm})$.

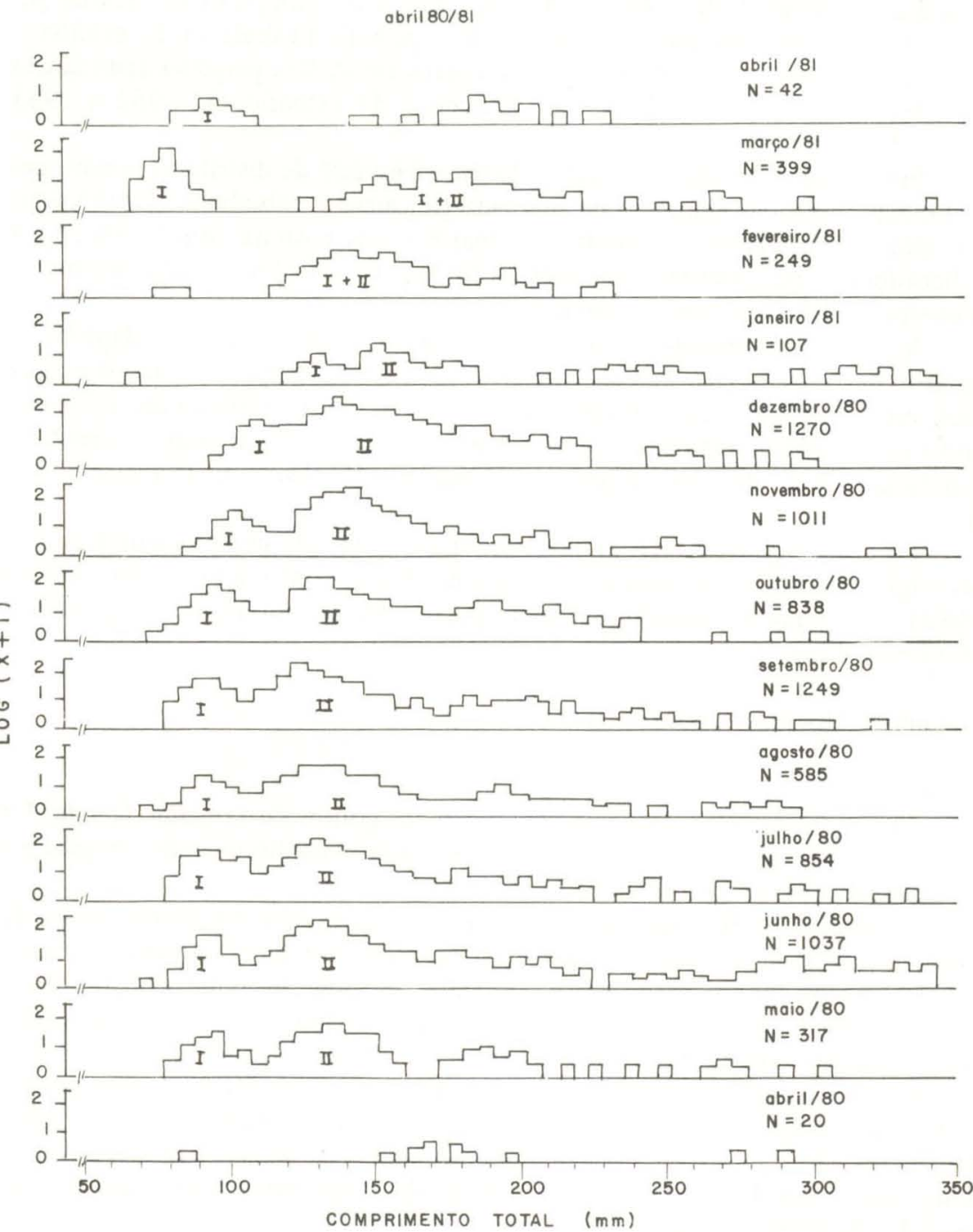

FIG. 6a - Distribuição mensal de freqüências de comprimento de Netuma barba, no estuário da Lagoa dos Patos (RS), no período de abril de 1980/81. 
Vol. 5(4), 1988

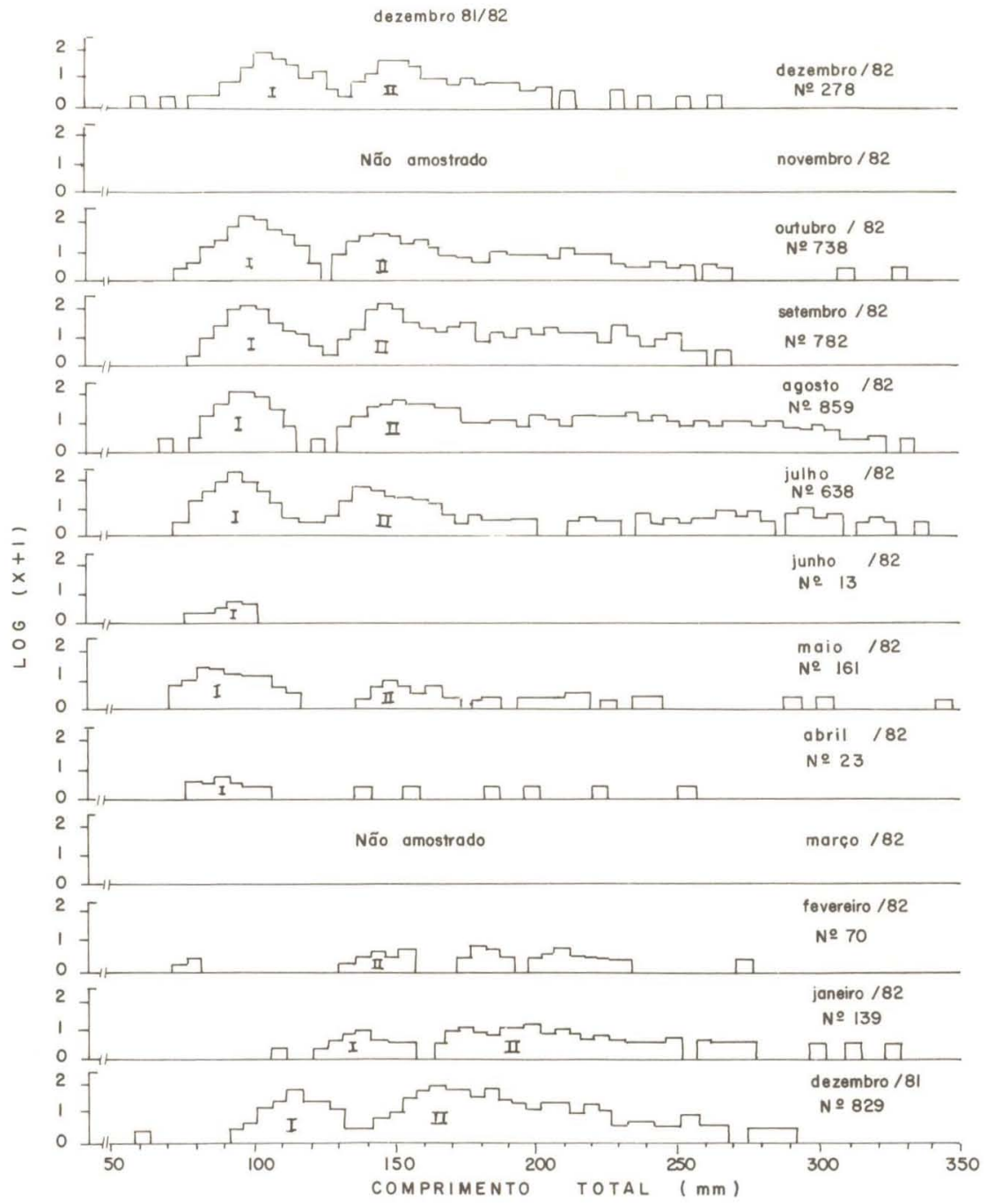

FIG. 6b - IDEM, para o período de 1981/82. 
Revta bras. Zool.

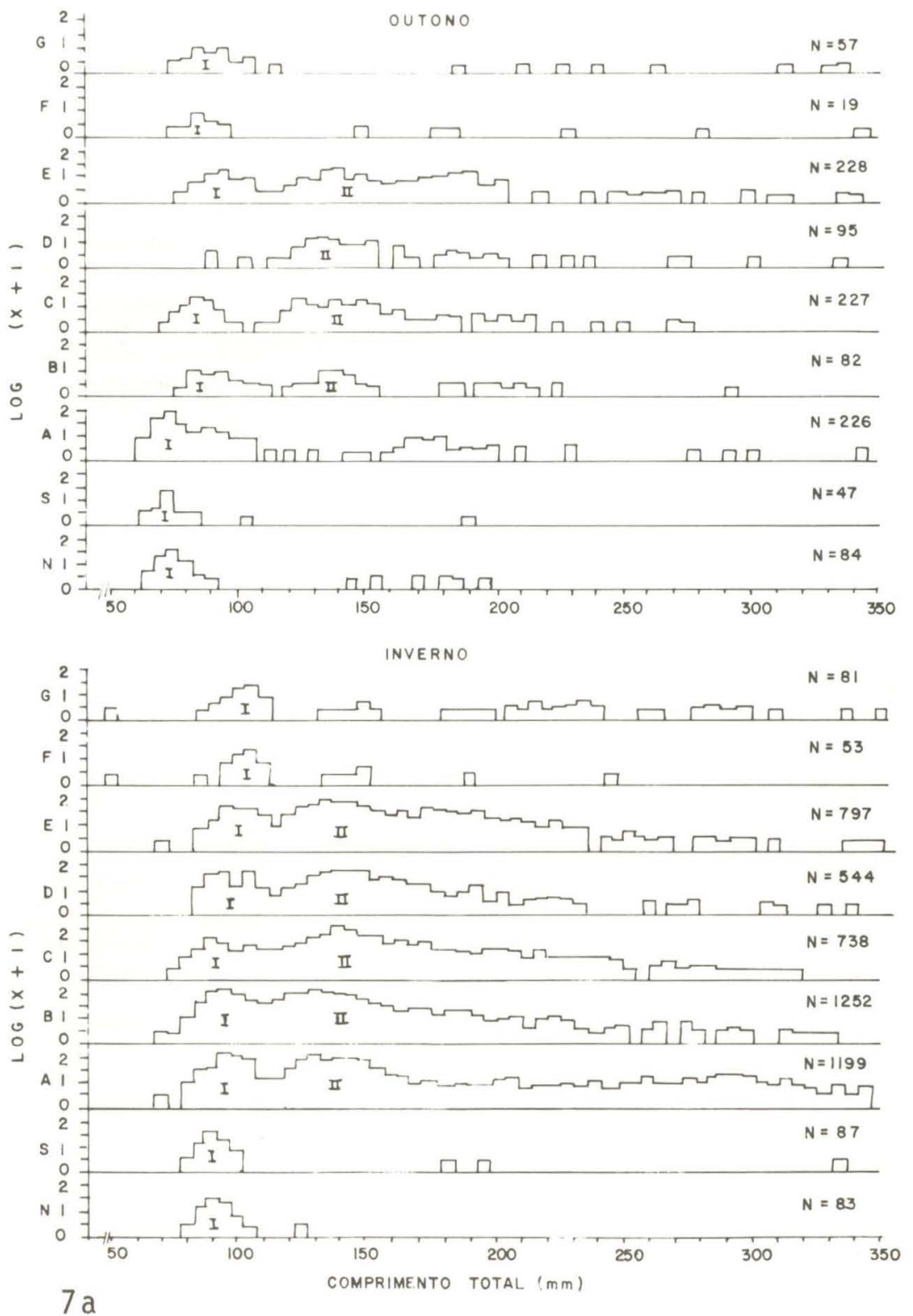

FIGS. 7a e 7b - Distribuição de freqüências de comprimento de Netuma barba, por zonas e por estações do ano no estuário da Lagoa dos Patos (RS). 
Vol. 5(4), 1988

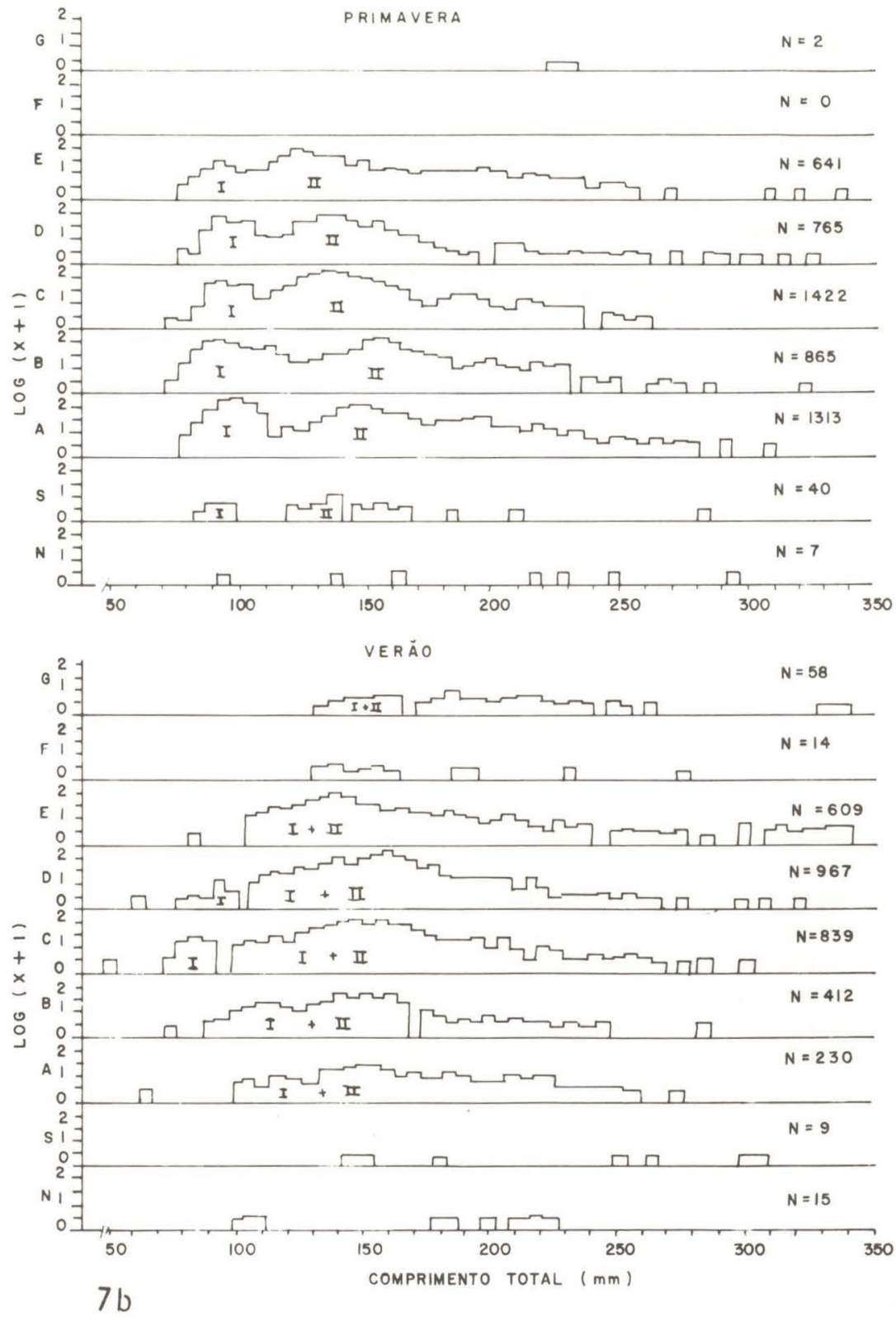


Revta bras. Zool.

As distribuições mensais de freqüências de comprimento nos dois ciclos anuais observados (abril 1980/1981 e dezembro 1981/1982) apresentaram modas mensais coincidentes, o que serve como indicação da validade deste método e da não ocorrência de variações acentuadas no crescimento dos bagres nestes diferentes anos.

Os resultados encontrados por Reis (1982) para crescimento de $N$. barba de 1 ano $(\mathrm{CT}=90 \mathrm{~mm})$ e 2 anos $(\mathrm{CT}=145 \mathrm{~mm})$ são inferiores a estes, o que pode ser atribuído às variações anuais no crescimento desta espécie, ocasionadas, provavelmente, por diferentes áreas de distribuição da população, ou à inadequação do método usado pela autora (retrocálculo) para determinação de comprimentos de bagres jovens.

Indivíduos nascidos no verão apareceram, no outono, em todo o estuário da lagoa, principalmente, na embocadura e área costeira (Fig. 7, moda I). No inverno, continuou a chegada desta classe de idade em toda área estudada, principalmente na área costeira, embocadura e intermediária. Na primavera, este grupo de peixes concentrou-se na embocadura e área intermediária e, no verão, pareceu deslocar-se um pouco mais para o interior da lagoa, ocorrendo principalmente na cabeceira e área intermediária.

$N$. barba no início do segundo ano de vida, no outono, foi encontrado, basicamente, na área intermediária (Fig. 7, moda II). No inverno, deslocou-se para a embocadura, sem chegar à área costeira. Individuos de idade superior a dois anos (CT superior a $250 \mathrm{~mm}$ ) concentraram-se, nesta estação do ano, na embocadura. Na primavera, $N$. barba, no segundo ano de vida, também se concentrou na área intermediária e, no verão, retornou à cabeceira, indo em seguida, provavelmente, para o interior da Lagoa dos Patos, à montante da área estudada.

Somente o grupo de $N$. barba no primeiro ano de vida ocorreu na área costeira, sendo que a classe de idade no segundo ano restringiu-se às áreas estuarinas do interior da lagoa. Esta grande abundância de indivíduos no primeiro ano de vida $(\mathrm{CT}=65$ a 90mm) na área costeira e embocadura (zonas $\mathrm{N}, \mathrm{S}, \mathrm{A}$ e B) e de indivíduos no segundo ano de vida (CT superior a $120 \mathrm{~mm}$ ) na embocadura e área intermediária (zonas A, B, C, D e E) no outono e inverno (Fig. 7) denota uma separação espacial por tamanho. Springer e Woodburn (1960) relatam que Galeichthys felis, de menor tamanho, é mais abundante em água menos salinas de enseadas da Flórida e, os de maior tamanho, em águas mais salinas. Isto é o contrário do que se constatou para $N$. barba no estuário da Lagoa dos Patos. Na primavera e verão, o que se verificou foi uma sobreposição espacial destas duas classes de idade na área intermediária, sugerindo que $N$. barba não abandona o estuário durante os dois primeiros anos de vida.

\section{Netuma planifrons}

Foram observados dois grupos de tamanhos (moda I e II) de $N$. planifrons, além de um pequeno número de indivíduos de maior comprimento total (Fig. 8).

O acompanhamento do grupo de menor tamanho (moda I) foi possível de março a janeiro. Em fevereiro, estes indivíduos foram escassos, não chegando a formar moda, porém, através da observação dos poucos peixes capturados neste período (Fig. 8) conclui-se que reaparecem no estuário, em maio, já com tamanho equivalente à moda II, a qual, também pode ser acompanhada até janeiro. 


\section{Vol. 5(4), 1988}

Estas modas parecem ser representativas das classes de idade de um e dois anos, visto a grande semelhança de tamanho com as de $N$. barba. Como se desconhecem informações do periodo de reprodução de $N$. planifrons, denominamos o grupo de menor tamanho, ao da moda I, e grupo de maior tamanho, ao da moda II.

N. planifrons apareceu nas amostragens em março (Fig. 8), apresentando $\mathrm{CT}=65$ a $90 \mathrm{~mm}(\widehat{\mathrm{CT}}=75 \mathrm{~mm})$. Em dezembro, quando tinha aproximadamente um ano de idade, apresentou $\mathrm{CT}=100$ a $120 \mathrm{~mm}(\overline{\mathrm{CT}}=110 \mathrm{~mm})$, enquanto os indivíduos de dois anos de idade apresentaram CT $=150$ a $190 \mathrm{~mm}(\overline{\mathrm{CT}}=$ $170 \mathrm{~mm})$

$N$. planifrons apresentou maior velocidade de crescimento do que $N$. barba visto que no início do primeiro ano de vida ambas as espécies apresentaram em março $\mathrm{CT}=65-90 \mathrm{~mm}(\overline{\mathrm{CT}}=75 \mathrm{~mm})$ e, em dezembro, $N$. planifrons apresentou $\mathrm{CT}=100-120 \mathrm{~mm}(\overline{\mathrm{CT}}=110 \mathrm{~mm})$ e $N$. barba, $\mathrm{CT}=90$ a $135 \mathrm{~mm}(\overline{\mathrm{CT}}=$ $100 \mathrm{~mm}$ ); neste mesmo mês, indivíduos no segundo ano de $N$. planifrons apresentaram CT $=150-190 \mathrm{~mm}(\overline{\mathrm{CT}}=170 \mathrm{~mm})$, enquanto $N$. barba, $\mathrm{CT}=140-$ $200 \mathrm{~mm}(\overline{\mathrm{CT}}=150 \mathrm{~mm})$.

Nesta espécie, a exemplo do que foi verificado para $N$. barba, também não foram observadas diferenças nas modas mensais entre os dois ciclos anuais observados (abril 1980/1981 e dezembro 1981/1982), o que valida os resultados encontrados.

O grupo de menor tamanho (Fig. 9, moda I) de $N$. planifrons apareceu, basicamente, na área costeira e embocadura durante o outono. No inverno, continuou a chegada deste grupo ao estuário, principalmente na área costeira. Na primavera, concentrou-se na área intermediária e embocadura. No início do verão (dezembro), foi registrado em todo estuário, com exceção da área costeira, e no fim do verão, pareceu sair do estuário, indo, provavelmente, para o interior da Lagoa dos Patos, a montante da área estudada.

O grupo de maior tamanho (Fig. 9, moda II) de $N$. planifrons permaneceu fora da área estudada até meados do outono, retornando ao estuário em maio, tendo sido registrado basicamente na área intermediária. No inverno, deslocou-se para a embocadura, sem chegar à área costeira. Na primavera, voltou para a área intermediária, sem chegar à cabeceira, permanecendo, ainda, parte deste grupo na embocadura. Depois de dezembro foram feitos poucos registros desta espécie na área estudada, com maiores ocorrências na embocadura.

Em $N$. planifrons ocorreu a mesma separação espacial por tamanho observada para $N$. barba no outono e inverno, quando o grupo de menor tamanho concentrou-se na área costeira, e enquanto o grupo de maior tamanho, na embocadura e área intermediária (Fig. 9). Também verificou-se grande sobreposição dos dois grupos de tamanho na área intermediária durante a primavera e verão.

\section{Genidens genidens}

Não foi observado número suficiente de peixes para caracterizar classes modais de tamanho (Figs. 10 e 11). Os menores individuos de G. genidens (Figs. 10 e 11) apresentaram CT de 45 a $70 \mathrm{~mm}(\overline{\mathrm{CT}}=55 \mathrm{~mm})$, tendo sido observado que estes peixes encontravam-se sendo incubados na boca dos pais, em fevereiro na cabeceira do estuário (zona G). 
Revta bras. Zool.

abril $80 / 81$
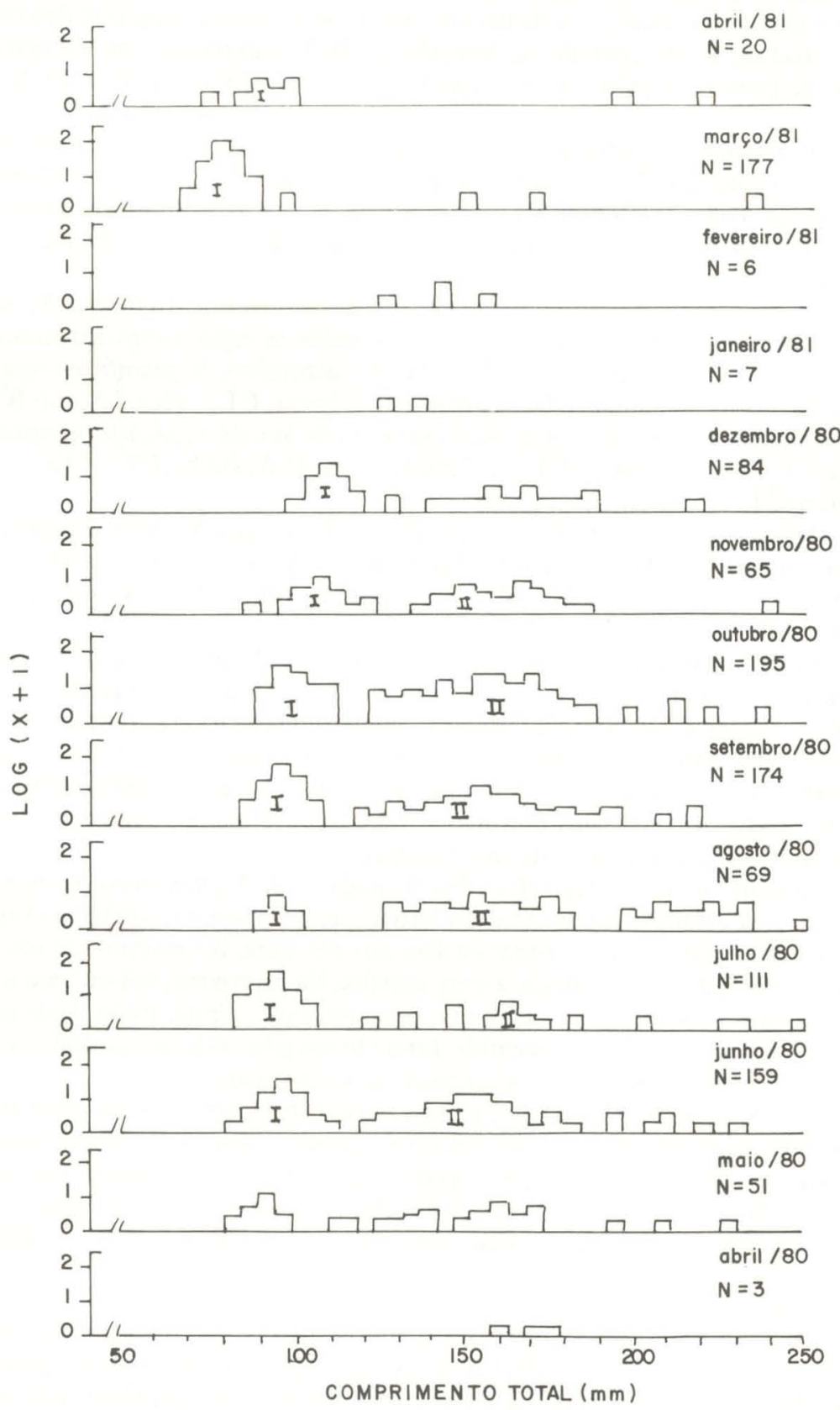

FIG. 8a - Distribuição mensal de freqüências de comprimento de Netuma planifrons, no estuário da Lagoa dos Patos (RS), no período de abril de 1980/81. 
Vol. 5(4), 1988
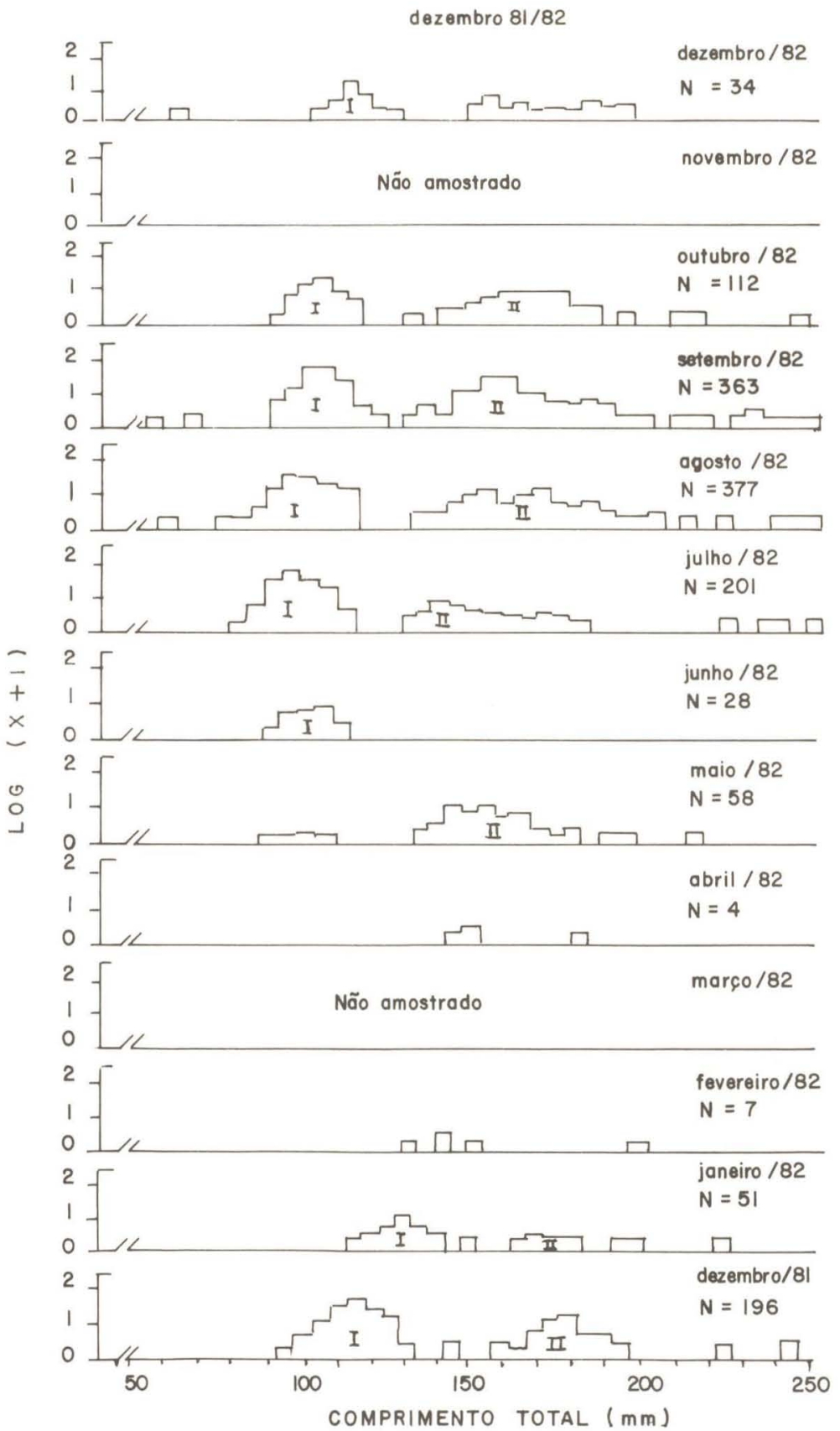

FIG. 8b - IDEM, para o período de dezembro de 1981/82. 
Revta bras. Zool.
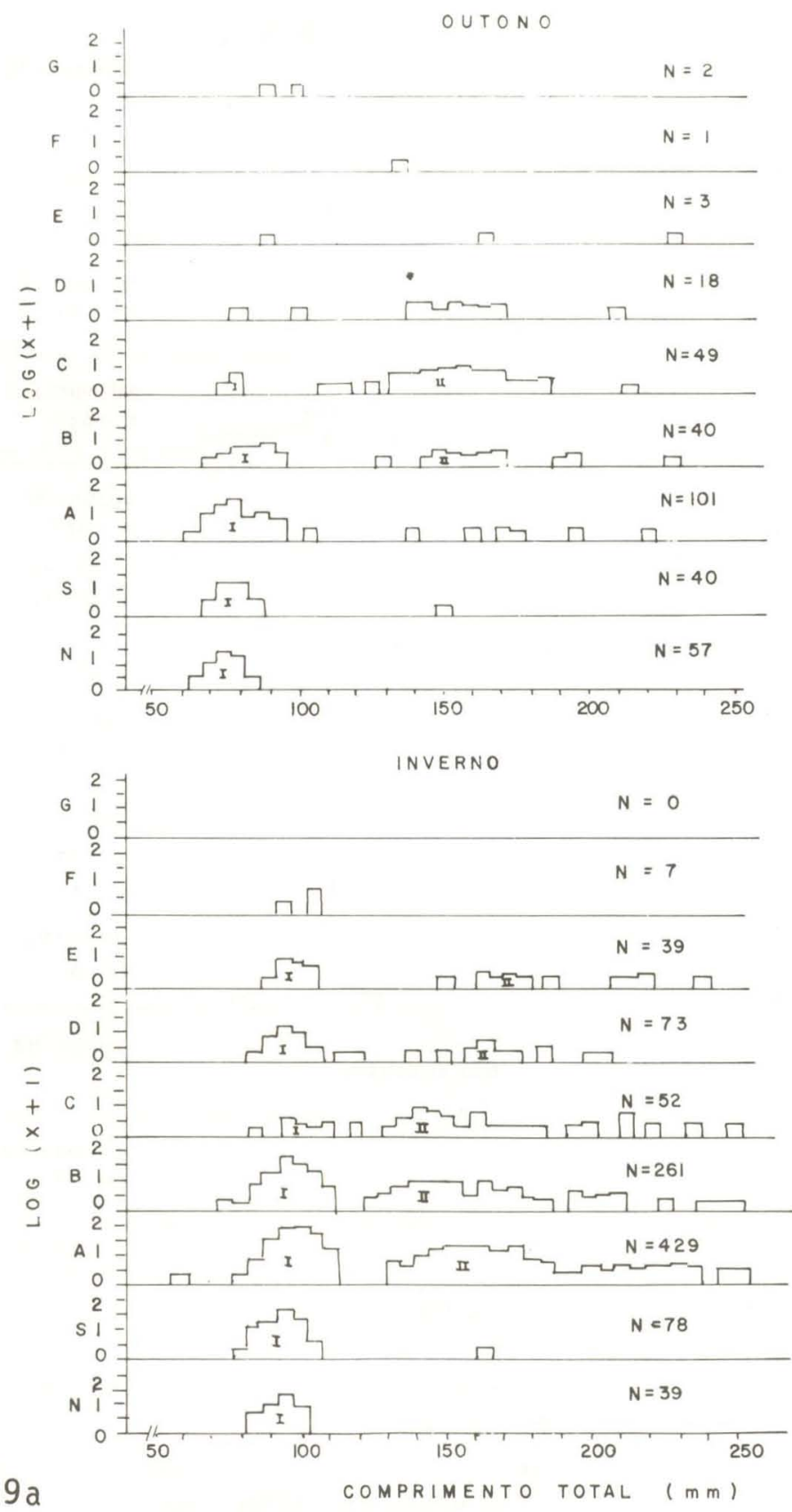

FIGS. 9a e 9b - Distribuição mensal de freqüências de comprimento de Netuma planifrons, por zonas e por estações do ano, no estuário da Lagoa dos Patos (RS). 
Vol. 5(4). 1988
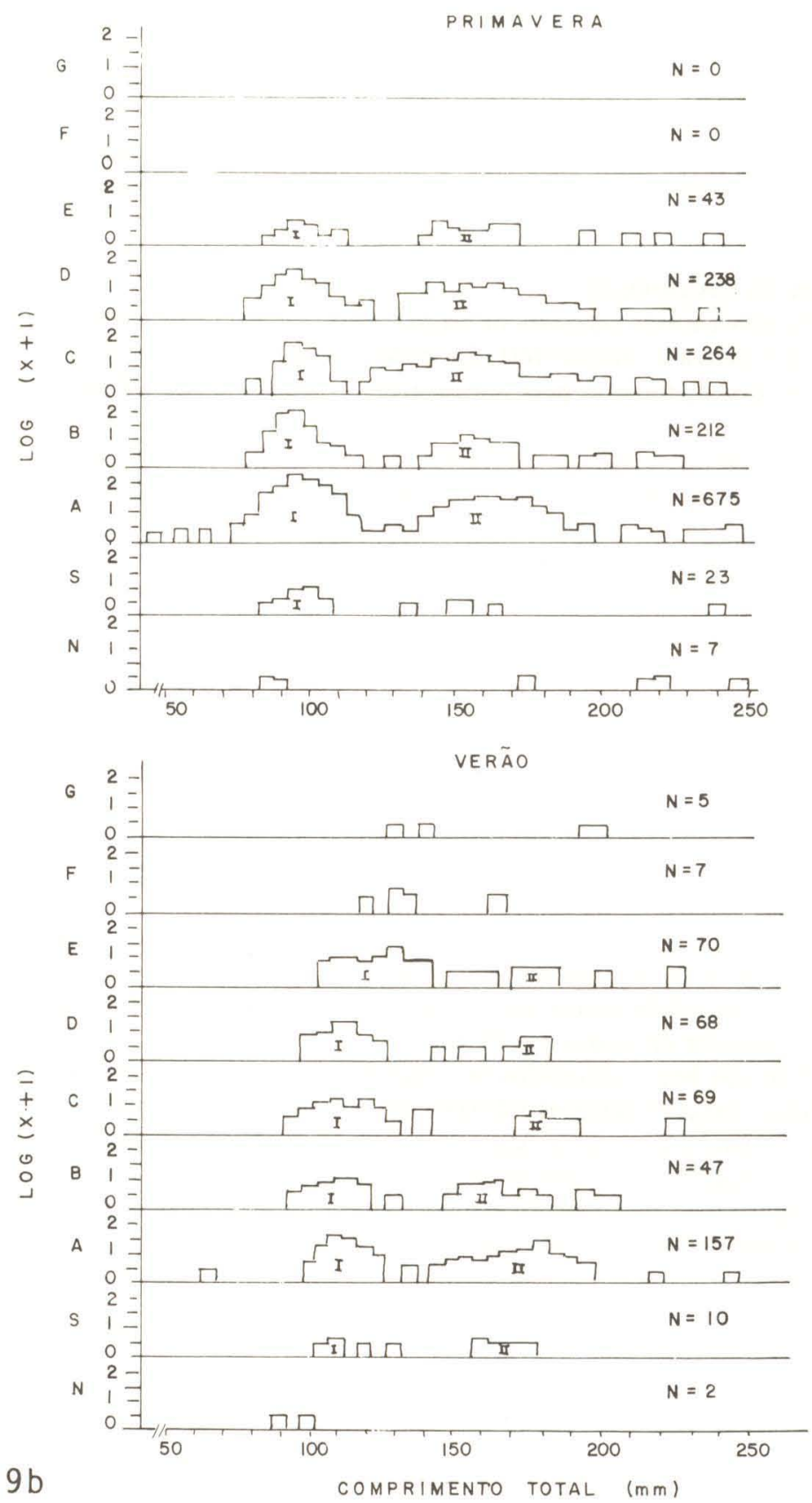
Indivíduos nascidos no verão, nas cabeceiras do estuário ou interior da Lagoa à montante da área estudada, permaneceram nestas áreas durante o outono (Fig. 11). No inverno, deslocaram-se para área intermediária e cabeceira. Na primavera, observou-se um deslocamento para o baixo estuário até a embocadura, continuando nesta área até o verão.

Indivíduos de maior tamanho, durante o outono, permaneceram na cabeceira, e deslocaram-se desta área à embocadura, no inverno, primavera e verão (Fig. 11).

\section{Natureza da Coexistência}

Os movimentos sazonais de bagres marinhos parecem obedecer uma estratégia reprodutiva e alimentícia do ciclo bioecológico, controlada por fatores abióticos, principalmente pela temperatura e salinidade (Lara-Dominguez et alii, 1981).

No caso do estuário da Lagoa dos Patos, não se observaram evidentes relações de dependências entre os fatores hidrográficos de temperatura, salinidade e oxigênio dissolvido com os movimentos sazonais dos bagres marinhos. $\mathrm{O}$ teor de oxigênio dissolvido está sempre em níveis relativamente elevados (acima de $5,0 \mathrm{mg} / \ell$ ), o que faz supor ter pouca influência como fator limitante da distribuição dos bagres.

A diminuição da temperatura, possivelmente, faz com que os três bagres, principalmente os do gênero Netuma, se movimentem do interior da lagoa para o estuário, e sua elevação faz com que os mesmos retornem ao interior da lagoa, daí suas maiores abundâncias no estuário durante o inverno e primavera quando ocorrem as menores temperaturas anuais.

As três espécies parecem se movimentar no estuário acompanhando o gradiente de baixa salinidade, embora tenham se registrado algumas exceções. $N$. barba e $N$. planifrons no início do primeiro ano de vida $(\mathrm{CT}=65-120 \mathrm{~mm})$ não parecem ter distribuição limitada pela salinidade uma vez que somente neste período são abundantes nas elevadas salinidades $(32 \% 0)$ da área costeira. Para $G$. genidens a salinidade parece ser um fator limitante de sua distribuição, restringindo-os ao in terior da Lagoa dos Patos.

Não são bem conhecidos os locais de desova dos bagres marinhos na Lagoa dos Patos: somente algumas informações para $N$. barba. Ihering (1897) menciona que $N$. barba desova em água doce no interior da Lagoa dos Patos e da Lagoa Mirim, próximo à embocadura de rios. Reis (1982) sugere que esta espécie desova em águas menos salinas do estuário, entre fins da primavera e início do verão. Estudos realizados em outras regiões indicam que peixes da família Ariidae desovam em águas de salinidade abaixo de $15 \%$ (Gunter, 1947; Yañez-Arancíbia et alii, 1976; Lara-Dominguez, 1981; Mishima e Tanji, 1983b).

A não ocorrência de $G$. genidens com $\mathrm{CT}=65-90 \mathrm{~mm}$ na área costeira $\mathrm{e}$ embocadura, onde foram mais abundante as espécies do gênero Netuma nesta faixa de comprimento total, serve como indicação de diferentes áreas de reprodução entre estes dois gêneros; G. genidens desova no interior da Lagoa dos Patos e os jovens provenientes destas desovas demoram maior tempo do que as espécies de Netuma para chegar à área baixa do estuário, e o fazem já com maior tamanho. Lara-Dominguez et alii (1981) constataram que Arius melanopus, após 


\section{Vol. 5(4), 1988}

a reprodução, abandonam as áreas de desova (sistema fluvio-lagunares) e são coletados, principalmente no interior da Lagoa dos Términos (México), onde a salinidade é mais elevada. Uma situação muito semelhante a esta parece ocorrer $\operatorname{com} N$. barba na Lagoa dos Patos.

$N$. barba e $N$. planifrons têm, provavelmente, os mesmos locais e épocas de desova, visto o aparecimento dos menores indivíduos nos mesmos períodos e locais do baixo estuário, quando ocorrem pela primeira vez nas capturas.

As três espécies, como é usual para a família Ariidae, realizam incubação oral. Segundo Devincenzi (1933) N. barba apresenta incubação gástrica, o que foi negado por Breder e Rosen (1966).

Não se sabe como jovens de $N$. barba deslocam-se dos locais de desova para a embocadura e área costeira; se por movimentos ativos ou se trazidos pelos pais (machos), ainda na fase de incubação oral, quando do retorno destes últimos ao mar. A grande quantidade de detritos encontrados em estômagos de embriões de $G$. genidens, cujos pais os incubavam na cabeceira do estuário, serve como indicação de que esta espécie pode sair e voltar à boca dos pais durante a incubação. É de se esperar que o mesmo ocorra com as espécies do gênero Netuma. Lee (1937) constatou que embriões de Galeichthys felis, em condições de laboratório, não saem da boca dos pais (machos). Gunter (1947), Ward (1957) e Breder e Rosen (1966) citam que embriões desta espécie podem sair e voltar à boca dos pais.

O período de incubação de $N$. barba é de, aproximadamente, três meses, tempo entre a desova (dezembro) e o aparecimento nas amostragens (março). Para esta hipótese ser verdadeira é necessário que os mesmos se encontrem durante este período na área estuarial, sob os cuidados dos pais, que, por sua vez, não são capturados pela arte de pesca empregada.

$N$. barba é o único dos três bagres marinhos que permanece no estuário durante os dois primeiros anos de vida; a partir do terceiro ano, parece deslocar-se para o interior da Lagoa dos Patos, juntando-se aos adultos. $N$. planifrons também tem início de vida no estuário, ausenta-se no fim do primeiro ano, indo, provavelmente, para o interior da lagoa (fevereiro a abril) e retorna ao estuário em maio; permanece nesta área até dezembro, para, a partir daí, não mais ocorrer nas capturas. G. genidens permanece na cabeceira do estuário e interior da lagoa, e só ocasionalmente frequenta o estuário em sua fase jovem, sem verificar-se sazonalidades de sua chegada e saída nesta área.

As migrações para fora do estuário de jovens do gênero Netuma de maior tamanho antes da chegada do grupo de menor tamanho (recrutas) em janeiro e fevereiro, parece constituir um mecanismo de evitar competição entre as classes de idade.

Constatou-se a existência de $N$. barba $(\mathrm{CT}=323$ a $605 \mathrm{~mm})$ e $N$. planifrons $(\mathrm{CT}=308-620 \mathrm{~mm})$ na plataforma continental do Rio Grande do Sul, em arrastos de fundo realizados com Navio-Oceanográfico "Atlântico Sul" (Cruzeiro 7/80; se tembro de 1980), o que indica que estes peixes migram para o mar quando adultos. Não observamos, neste Cruzeiro, $G$. genidens, porém sua presença nesta área foi registrada por Benvegnú-Lé (1978), embora em pequena abundância.

G. genidens tem ciclo de vida diferente das espécies do gênero Netuma; es- 
Revta bras. Zool. ta espécie se separa espacialmente de $N$. barba e $N$. planifrons e se distribui, principalmente na cabeceira e interior da Lagoa dos Patos. Apenas jovens de maior tamanho coexistem com jovens de $N$. barba e $N$. planifrons no estuário.

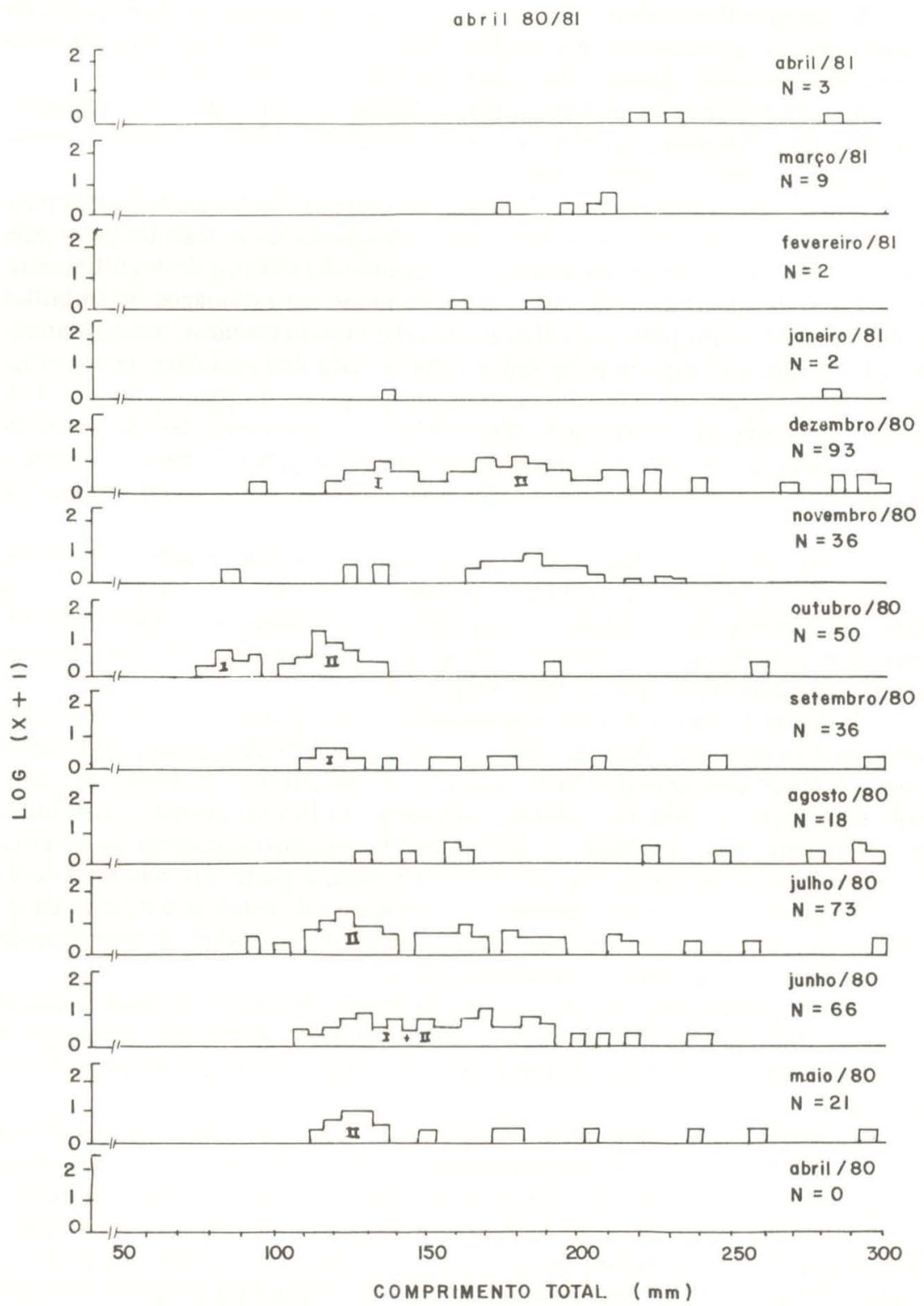

FIG. 10a - Distribuição mensal de freqüências de comprimento de Genidens genidens, no estuário da Lagoa dos Patos (RS), no período de abril de 1980/81. 
Vol. 5(4), 1988

Uma hipótese do ciclo de vida de $N$. barba é sugerida (Fig. 12). Indivíduos nascidos no verão, na área alta do estuário, durante o primeiro outono e inverno. deslocam-se para águas mais salinas $(32 \%)$ da área costeira, e retornam à área

dezembro $81 / 82$

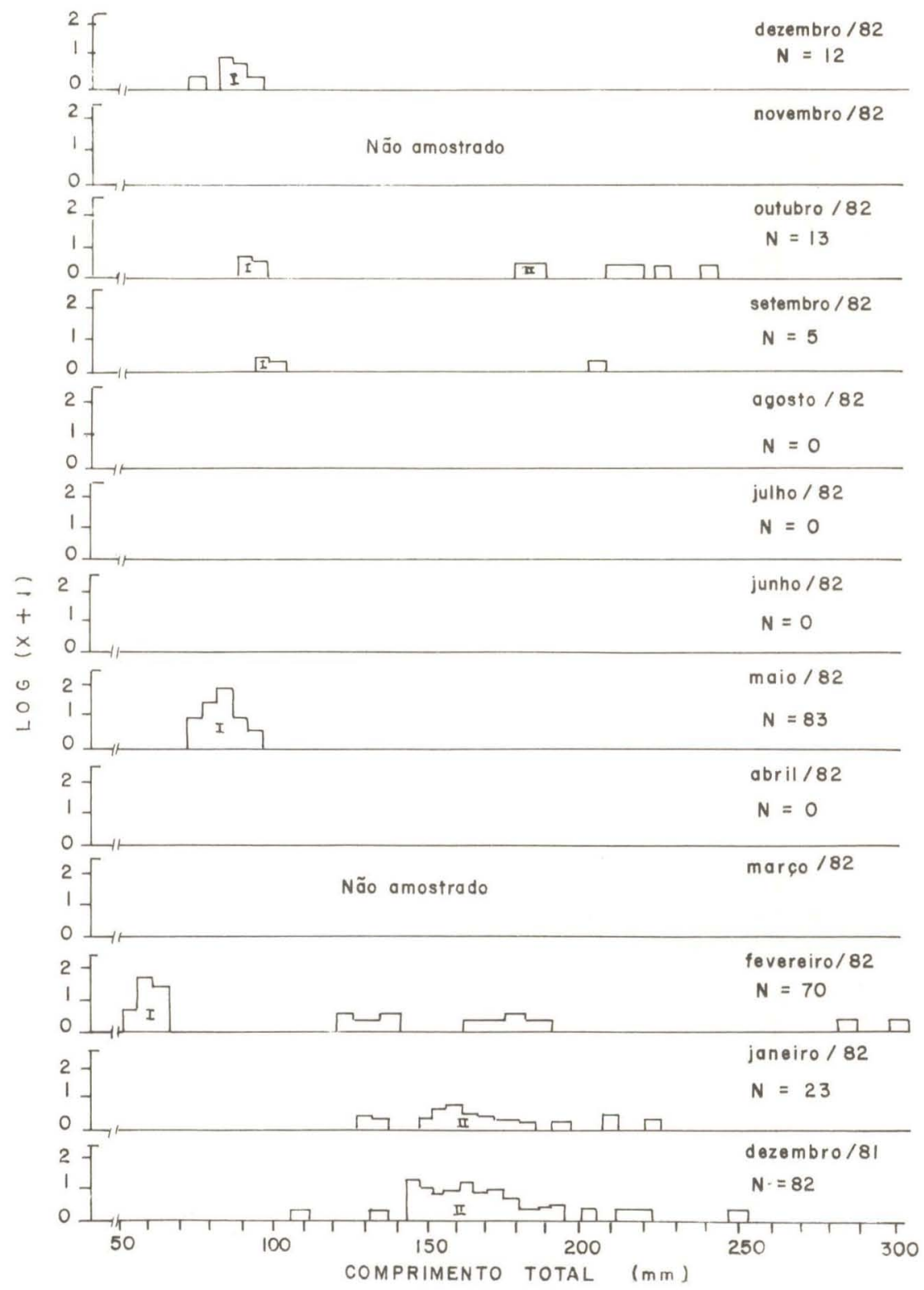

FIG. 10b - IDEM, no período de dezembro de 1981/82. 
Revta bras. Zool. intermediária e cabeceiras do estuário na primavera e verão. No início do segundo ano de vida (verão e outono) deslocam-se, novamente, para a área da embocadura, mas não chegam à área costeira. Na primavera, volta à área in terme-

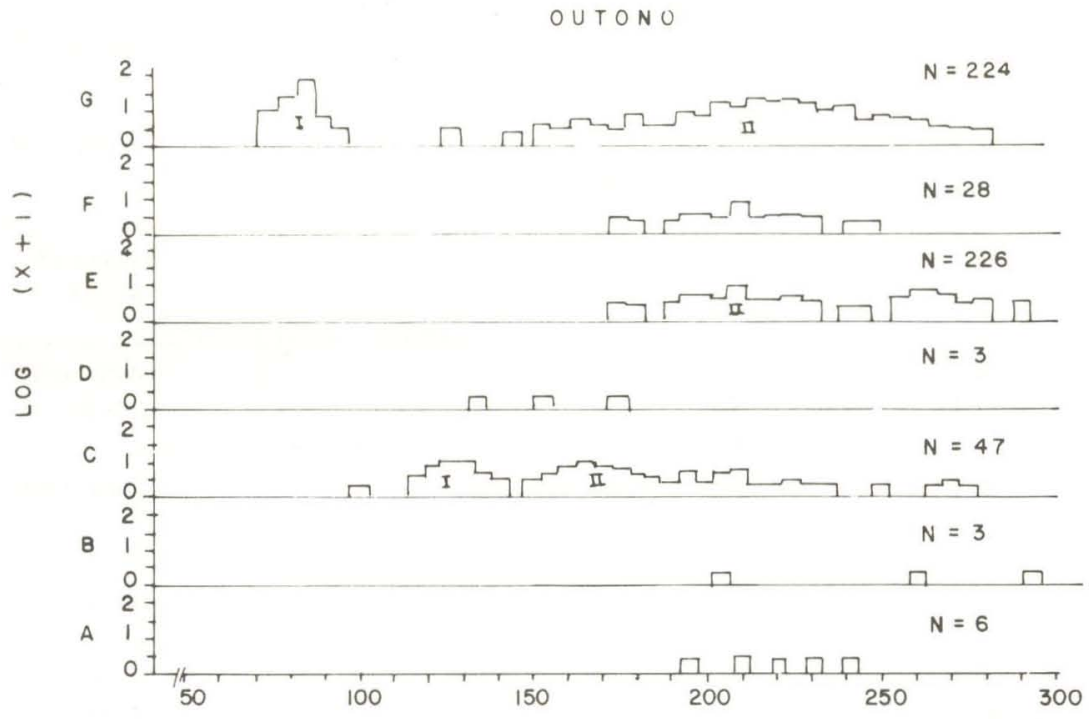

INVERNO

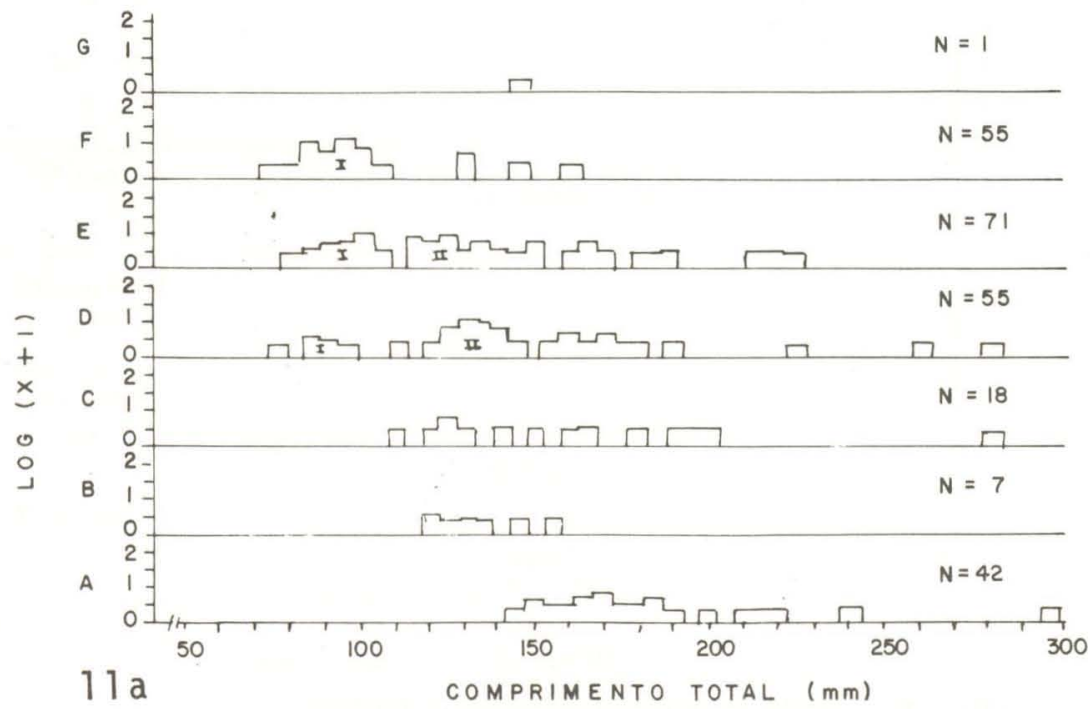

FIGS. 11a e 11b - Distribuição de freqüências de comprimento de Genidens genidens, por zonas e por estações do ano, no estuário da Lagoa dos Patos (RS). 
Vol. 5(4), 1988

diária e cabeceira do estuário, e no verão, já são subadultos (idade superior a 2 anos) e juntam-se aos adultos no interior da Lagoa dos Patos. Subadultos e adultos, após a época de reprodução, migram para o mar, e retornam ao estuário no fim do próximo inverno, para desova.

Para $N$. planifrons e $G$. genidens não foi possível a formulação de hipótese do ciclo de vida devido à menor ocorrência destas espécies nas amostragens, como também por não existir, na literatura, referências sobre a biologia destes

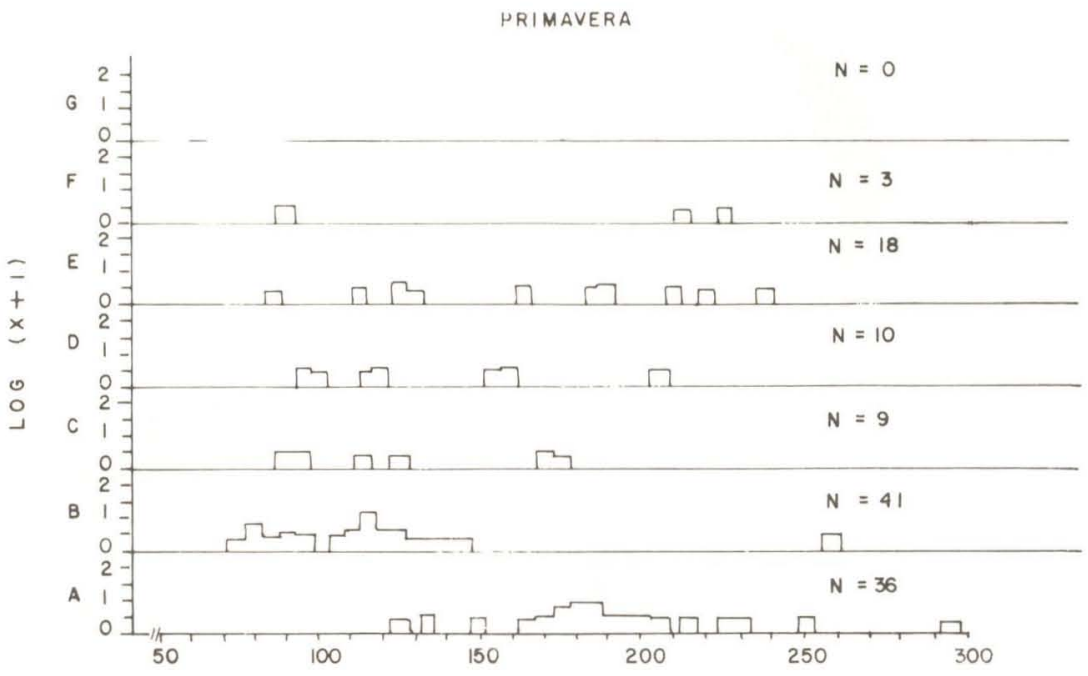

VER ÃO

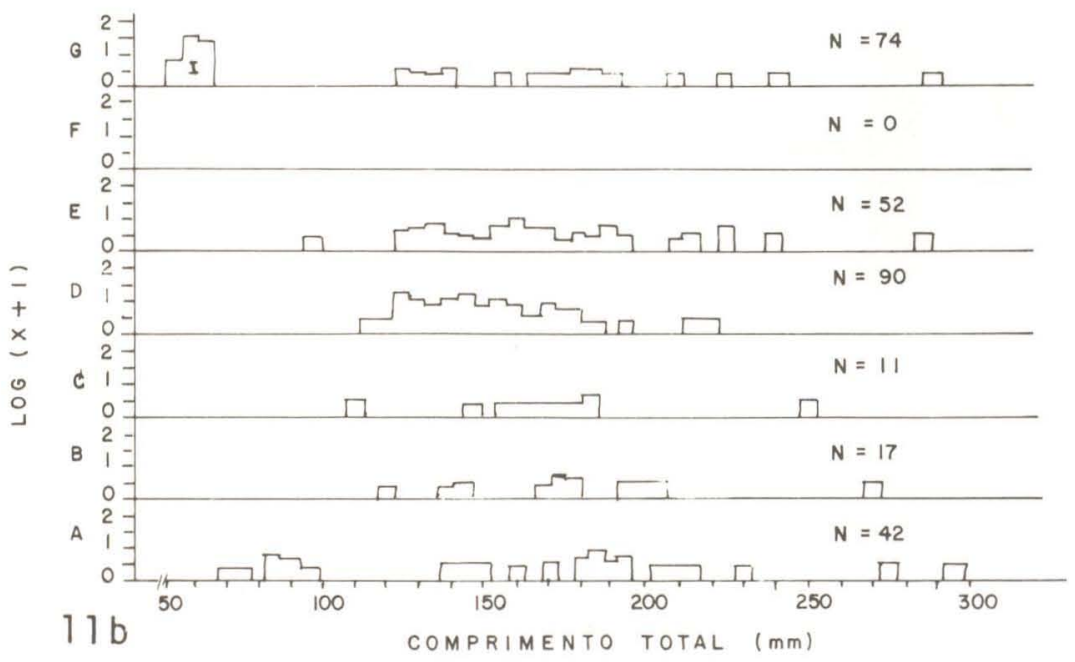


Revta bras. Zool.

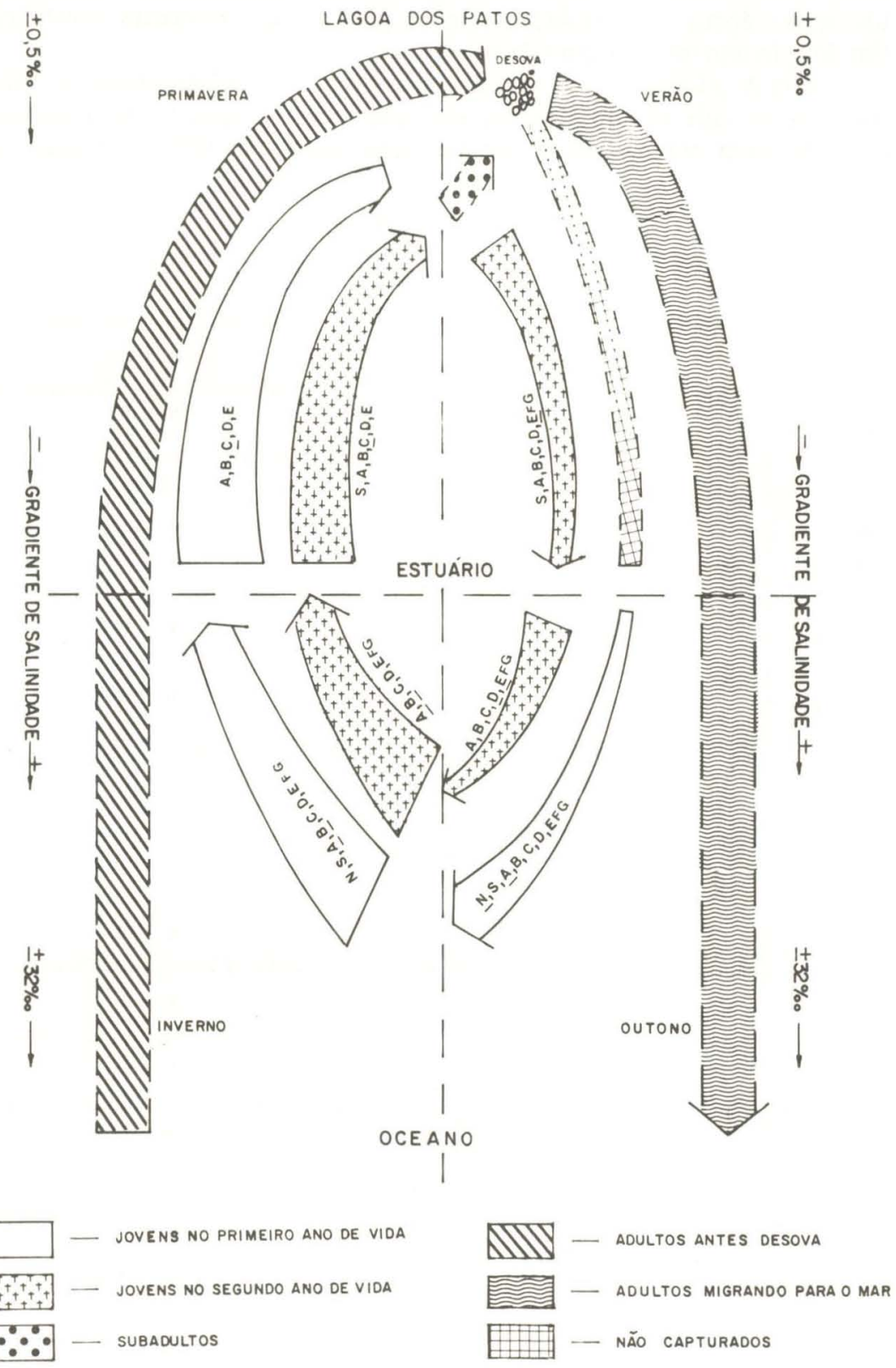

FIG. 12 - Diagrama hipotético do ciclo de viđa de Netuma barba, no estuário da Lagoa dos Patos (RS). 
Vol. 5(4), 1988

peixes, como locais e períodos de reprodução e áreas de distribuição dos adultos.

Constatada a coexistência de jovens de bagres marinhos, é possível que a separação ecológica (alimentar e espacial) seja mais acentuada nos adultos. Estes peixes têm em comum área de criação e, provavelmente também, áreas de desova. Futuros estudos poderão esclarecer outros aspectos do ciclo de vida, notadamente a migração dos jovens e subadultos das áreas de criação para os habitats dos adultos, que constitui uma parte da vida destes bagres ainda desconhecida.

\section{AGRADECIMENTOS}

Ao Dr. Labish N. Chao, pela orientação e valiosas sugestões. Aos Profs. Luis Eduardo Pereira e João P. Vieira Sobrinho, pela colaboração nos trabalhos de coleta e processamento do material. Ao Comandante Paulo Borges e à tripulação da Lancha Oceanográfica LARUS e ao laboratorista Arthur Oscar D. Lima, pelo apoio nos trabalhos de campo e de laboratório, respectivamente.

\section{REFERÊNCIAS}

Araújo, F.G. 1983. Distribuição, abundância, movimentos sazonais e hábitos alimentares de bagres marinhos (Siluriformes, Ariidae) no estuário da Lagoa dos Patos (RS), Brasil. $89 \mathrm{pp}$. (Dissertação de Mestrado). Fundação Universidade do Rio Grande, Depto. de Oceanografia.

Benvegnú-Lé, G. de Q. 1978. Distribuição dos peixes teleósteos marinhos demersais na plataforma continental do Rio Grande do Sul. 94pp. (Tese de Doutoramento). Universidade de São Paulo, Instituto de Biociências.

Berra, T.M. 1981. An atlas of distribution of the freshwater families of the world. University of Nebraska Press. Lincoln and London. 197 pp.

Blaber, S.J.M.\& T.G. Blaber. 1980. Factors affecting the distribution of juvenile estuarine and inshore fish. J.Fish. Biol, 17:143-162.

Breder, C.G. \& D.E. Rosen. 1966. Modes of reproduction in fisheslow fishes breed. Nat. Hist. Press. New York, pp. 244-249.

Castello, JP. (Coord.). 1976 a 1978. Relatórios dos cruzeiros, Projeto Lagoa. Fundação Universidade do Rio Grande, Base Oceanográfica Atlântica. Séries relatórios, 1 a 15.

Castello, J.P. \& O.O. Moller. 1978. On the relationship between rainfall and shrimp production in the estuary of Patos Lagoon (Rio Grande do Sul, Brasil). Atlântica, 3 (único): $67-74$.

Chao, L.N.; L.E. Pereira, J.P. Vieira; M.A. Bemvenuti \& L.P.R. Cunha. 1982. Relação preliminar dos peixes estuarinos e marinhos da Lagoa dos Patos e região costeira adjacente; Rio Grande do Sul, Brasil. Atlântica, 5(1):67-75.

Craig, I.D.H. 1980. Contribuição ao conhecimento de fauna íctica costeira da região de Peruı́be, São Paulo. I: familia Ariidae. Revta bras. Biol., 40(4) :755-758.

Devincenzi, GJ. 1933. La perpetuacion de la espécie en los peces sudamericanos. An Mus. Hist. Nat. Montevideo, sér. 2a., 4(2):1-28. 
Revta bras. Zool.

Eigenmann, C.H. \& R.S. Eigenmann. 1890. A revision of the south american nemathognathi, or cat-fishes. California Academy of Science. San Francisco, 94pp.

Figueiredo, J.L. \& N.A. Menezes. 1978. Manual de peixes marinhos do sudeste do Brasil. II. Teleostei (1). Universidade de São Paulo, Museu de Zoologia. 110pp.

Gunter, G. 1947. Observations on breeding of the marine catfish Galeichthys felis (Linnaeus). Copeia, 4:217-223.

Herz, R. 1977. Circulação das águas de superfície da Lagoa dos Patos. (Tese de Doutoramento) Universidade de São Paulo, Faculdade de Filosofia, Letras e Ciências Humanas. $266 \mathrm{p}$.

Higuchi, H.; E.G. Reis \& F.G. Araújo. 1981. Uma nova espécie de bagre marinho do litoral do Rio Grande do Sul e considerações sobre o gênero nominal Netuma Bleeker, 1858 no Atlântico Sul Ocidental (Siluriformes, Ariidae). Atlântica, 5(1):1-15.

Ihering, H. von. 1885. Die Lagoa dos Patos. Bremen, Deutsche Geographische Blatter, p. 164-203.

Ihering, H. von. 1897. Os peixes da costa do mar do Estado do Rio Grande do Sul. Revta Mus. Paul., São Paulo, 2:25-63.

Jones, P.W.; F.D. Martin, \& J.D. Hardy. 1978. Development of fishes of mid-Atlantic bight an athas of egg, larval an juvenile stages, Ariidae. Biol. Serv. Progr. U S. Dept. Interior, 1:301-307.

Kantin, R. \& M.G.Z. Baumgarten. 1982. Observações hidrográficas no estuário da Lagoa dos Patos: distribuição e flutuações dos sais nutrientes. Atlântica, 5(1):76-92.

Lara-Dominguez, A.L.; A. Yañez-Arancibia \& F.A. Linhares. 1981. Biolc gia y ecologia del bagres Arius melanopus Gunther en Laguna de Términos, sur del Gulfo de México (pisces: Ariidae). An. Inst. Cienc. del Mar y Limnol. Univ. Nat. Autón. México, 8(1): 267-304.

Lee, G. 1937. Oral gestation in the marine catfish Galeichthys felis. Copeia, (1):49-56.

López, R.P. \& N.B. Bellisio. 1965. Contribución al conocimento del Tachysurus barbus (Lacepéde), bagre del mar argentino (Pisces: Ariidae). Anais do II Congr. Lat. Amer. de Zool., 2:145-153.

Markle, D.F. 1976. The seasonality of availability and movements of fishes in the channel of the York River, Virgínia. Chesapeake Sci. 17:50-55.

Mishima, M. \& S. Tanji. 1981. Distribuição geográfica dos bagres marinhos (Osteichthyes, Ariidae) no complexo estuarino lagunas de Cananeia ( $\left.25^{\circ} \mathrm{S}, 48^{\circ} \mathrm{W}\right)$. B. Inst. Pesca, 8 (único):157-172.

Mishima, M. \& S. Tanji. 1982. Nicho alimentar de bagres marinhos (Teleostei; Ariidae) no complexo estuarino lagunar da Cananéia $\left(25^{\circ} \mathrm{S}, 48 \mathrm{OW}\right)$. B. Inst. Pesca, 9(único):131140.

Mishima, M. \& S. Tanji. 1983a. Fatores abióticos relacionados à distribuição e abundância de bagres marinhos (Osteichthyes, Ariidae) no complexo estuarino lagunar de Cananéia (250W, 48 oW). B. Inst. Pesca, 10(único):17-27.

Mishima, M. \& S. Tanji. 1983b. Maturação e desova de bagres marinhos (Osteichthyes, Ariidae) do complexo estuarino lagunar de Cananéia $\left(25^{\circ} \mathrm{W}, 48^{\circ} \mathrm{W}\right)$. B. Inst. Pesca, 10 (único):129-141. 
Vol. 5(4), 1988

Motta, V.F. 1969. Relatório diagnóstico sobre a melhoria e o aprofundamento do acesso pela barra do Rio Grande. Porto Alegre, UFRGS, Inst. Pesq. Hidráulico, 114pp.

Poli, C.R. 1973. Os bagres do litoral de Santa Catarina e Rio Grande do Sul - Brasil (Ostariophysi, Siluriformes, Bagridae). Iheringia, Zool., 42:3-13.

Reis, E.G. 1982. Idade, crescimento e reprodução de Netuma barba (Siluriformes, Ariidae) no estuário da Lagoa dos Patos (RS). (Dissertação de Mestrado). Fundação Universidade do Rio Grande. 114 pp.

Ribeiro, A.M. 1915. Fauna brasiliense. Peixes. Thachysuridae. Arch. Mus. Nacional, 3(3): 336-352.

Sielfeid, K.E.H. 1979. Nuevo registro de Netuma barbus (Lacepède) 1803 para águas chilenas (Pisces: Siluriformes). Ans. Inst. Pat., Punta Arenas (Chile), 10:189-192.

Springer, V.G. \& K.D. Woodburn. 1960. An ecological estudy of the fishes of the Tampa Bay. Prof. Paper Sér., Flórida, 1:104.

Strickland, J.D.H. \& T.R. Parsons. 1972. A practical handbook of seawater analysis. Bull. Fish. Res. Board Can., 167:1-31.

SUDEPE. 1982. Produção pesqueira do Estado do Rio Grande do Sul, pesca artesanal e industrial. Superintendência do Desenvolvimento da Pesca. Estado do Rio Grande do Sul. Rio Grande.

Taylor, W.R. \& N.A. Menezes. 1978. Ariidae. In: Fischer, W. ed. FAO species identification sheets for fishery purpose. Western Central Atlantic (fishing area 31). Rome FAO. pag. var.

Tommasi, L.R. 1965. Lista dos bagres marinhos e de água salobra do Brasil. Contr. Inst. Oceanogr., USP, sér. Ocean. Biol., 10(1):1-11.

Villaseñor, L.I.G. 1972. Aspectos biológicos y distribución de algunas espécies del noroeste de México. (Dissertação de Mestrado). Univ. Nac. Auton. de México, Fac. de Ciências, $80 \mathrm{pp}$.

Ward, J.W. 1957. The reproduction and early development of the sea catfish, Galeichthys felis, in the Biloxi (Mississipi) Bay. Copeia, 4:295-298.

Yañez-Arancibia, A.; J. Curiel-Gomez \& V.L. Yañez. 1976. Prospeccion biológica y ecológica del bagre marino Galeichthys caerulescens (Guntter) en el sistema lagunar costero Guerrero, México (Pisces: Ariidae), An. Centro de Ciências del Mar y Limnol., Univ. Auton. México, 3(1):125-180. 